\title{
Boat noise affects meagre (Argyrosomus regius) hearing and vocal behaviour
}

\author{
Manuel Vieira ${ }^{\text {a,b, }}$, Marilyn Beauchaud ${ }^{\mathrm{c}}$, M. Clara P. Amorim ${ }^{\mathrm{b}}$, Paulo J. Fonseca ${ }^{\mathrm{a}}$ \\ a Departamento de Biologia Animal and cE3c_Centre for Ecology, Evolution and Environmental Changes, Faculdade de Ciências, Universidade de Lisboa, Lisbon, Portugal \\ ${ }^{\mathrm{b}}$ MARE_Marine and Environmental Sciences Centre, ISPA, Instituto Universitário, Lisbon, Portugal, and Departamento de Biologia Animal, Faculdade de Ciências, \\ Universidade de Lisboa, Lisbon, Portugal \\ ${ }^{\mathrm{c}}$ Equipe de Neuro-Ethologie Sensorielle; (ENES/CRNL, CNRS UMR 5292, Inserm UMR S 1028) Faculté des Sciences et Techniques, Université Jean-Monnet de Lyon/ \\ Saint-Etienne, Saint-Etienne, France
}

\section{A R T I C L E I N F O}

\section{Keywords:}

Acoustic communication

Marine noise pollution

Sciaenidae

Anthropogenic noise

Fish

\begin{abstract}
A B S T R A C T
Aquatic noise has increased in last decades imposing new constraints on aquatic animals' acoustic communication. Meagre (Argyrosomus regius) produce loud choruses during the breeding season, likely facilitating aggregations and mating, and are thus amenable to being impacted by anthropogenic noise. We assessed the impact of boat noise on this species acoustic communication by: evaluating possible masking effects of boat noise on hearing using Auditory Evoked Potentials (AEP) and inspecting changes in chorus sound levels from free ranging fish upon boat passages. Our results point to a significant masking effect of anthropogenic noise since we observed a reduction of ca. $20 \mathrm{~dB}$ on the ability to discriminate conspecific calls when exposed to boat noise. Furthermore, we verified a reduction in chorus energy during ferryboat passages, a behavioural effect that might ultimately impact spawning. This study is one of few addressing the effects of boat noise by combining different methodologies both in the lab and with free ranging animals.
\end{abstract}

\section{Introduction}

Man-made noise can affect animal behaviour and physiology (Graham and Cooke, 2008; Picciulin et al., 2010; Bruintjes and Radford, 2013; Holles et al., 2013; Voellmy et al., 2014; Shannon et al., 2015; de Jong et al., 2020; Jerem and Mathews, 2021) and is now acknowledged as a chronic source of pollution that is changing soundscapes worldwide (European Commission, 2008; Barber et al., 2009; Normandeau, 2012; Senzaki et al., 2020, Duarte et al., 2021). While acoustic signals and auditory mechanisms have evolved under natural ambient noise (Tuset et al., 2016), increased anthropogenic noise is imposing new constraints on communication. This additional noise source can cause a reduction in animals' communication range and impair the detection of key signal features (insects: Klappert et al., 2009; fish: Ladich, 2013; amphibians: Bee and Swanson, 2007; birds: Lohr et al., 2003; marine mammals: Erbe et al., 2016; Rosa and Koper, 2018). Furthermore, anthropogenic noise can cause a wide range of effects, such as increased stress, behavioural avoidance, temporary threshold shifts, hearing loss or even death (Popper and Hastings, 2009; Barber et al., 2009; Shannon et al., 2015; de Jong et al., 2020; Breitzler et al., 2020).

Noise pollution is known to affect insects (Bowen et al., 2020), fishes
(Popper and Hastings, 2009; de Jong et al., 2020), amphibians (Simmons and Narins, 2018), birds (Brumm and Zollinger, 2013), and mammals, both terrestrial (e.g. Egnor and Hauser, 2006; Tressler and Smotherman, 2009; Barber et al., 2009) and marine (e.g. Richardson et al., 2013; Erbe et al., 2016). For example, in insects, some species near noisy roads increase the frequency of their calls (Lampe et al., 2012) or show fine-scale temporal avoidance to the noise produced by vehicles (Gallego-Abenza et al., 2020), while others reduce the overall production of advertisement calls when in noise (Costello and Symes, 2014). Studies in anurans have shown that some species change the temporal or spectral features of the calls in the presence of noise (Sun and Narins, 2005; Lengagne, 2008; Cunnington and Fahrig, 2010; Alloush et al., 2011; Roca et al., 2016; Caorsi et al., 2017), and/or avoid the periods predominated by anthropogenic noise (Herrera-Montes and Aide, 2011; Vargas-Salinas et al., 2014). Birds in noisy areas have been found to sing more at night, when it is quieter (Fuller et al., 2007; Arroyo-Solís et al., 2013), but the presence of fine scale changes in timing to avoid intermittent noise is not clear (Gil and Brumm, 2014). Nevertheless, traffic noise can decrease reproductive success in birds, provoking also changes in behaviour and nesting location (Halfwerk et al., 2011; Kight et al., 2012; Injaian et al., 2018; Senzaki et al., 2020). In marine mammals,

\footnotetext{
* Corresponding author at: Departamento de Biologia Animal and cE3c_Centre for Ecology, Evolution and Environmental Changes, Faculdade de Ciências, Universidade de Lisboa, Lisbon, Portugal.

E-mail address: manuel_1990_v@hotmail.com (M. Vieira).
} 
some species also alter their vocalizations in the presence of noise (Miller et al., 2000; Castellote et al., 2012), while others change the calling rate (Van Parijs and Corkeron, 2001; McKenna, 2011).

Investigating the impact of noise on fish species is also particularly relevant, specially at sensitive areas located in highly human populated coastal and estuarine waters, where boats and ships are the most common sources of anthropogenic noise (Pine et al., 2016). In these regions it is more likely that fish are chronically exposed to sounds at lower intensities, which may cause behavioural rather than physical effects (e. g., Slabbekoorn et al., 2010). Furthermore, boat noise usually overlaps with the frequency range of fish hearing and sound production (Kunc et al., 2016; Stanley et al., 2017), and can thus contribute to the masking of acoustic signals and cues, with potential direct impact on fish acoustic communication (Dooling et al., 2015). Note that fishes use sound to interpret their surroundings (including the detection of predator and prey; Remage-Healey et al., 2006; Popper and Hawkins, 2019), and several species produce sounds in contexts such as courtship or spawning (Amorim et al., 2015) and may rely on acoustic communication for successful breeding (Vasconcelos et al., 2012). A few studies revealed significant shifts of hearing thresholds due to boat noise masking (Vasconcelos et al., 2007; Codarin et al., 2009). Furthermore, Codarin et al. (2009) showed that in Chromis chromis and Sciaena umbra the sound detection threshold to conspecific calls increased by ca. $20 \mathrm{~dB}$ in the presence of boat noise. A limited number of studies have shown that exposure to boat noise might also alter calling behaviour (de Jong et al., 2018; Picciulin et al., 2012; La Manna et al., 2016; Ceraulo et al., 2021). Interestingly, exposure to boat noise has resulted either in a suppression of calling in the painted goby and black drum (de Jong et al., 2018; Ceraulo et al., 2021) or in an increase in calling activity in the brown meagre (Picciulin et al., 2012). Noise can thus interfere with acoustic communication in fish as it may affect either the ability to hear and/or impact sound production. Under these conditions noise can ultimately impact fish fitness (Sierra-Flores et al., 2015; Nedelec et al., 2017; de Jong et al., 2018; Blom et al., 2019).

Sciaenidae is one of the largest families of vocal fishes (Chao, 1986), known for the conspicuous chorusing behaviour associated with the breeding season (e.g., Luczkovich et al., 1999; Parsons et al., 2013). The meagre, Argyrosomus regius, is a semi-pelagic sciaenid with a high commercial value, being farmed in several countries since the 1990s (Monfort, 2010). Adults migrate to coastal reproductive areas such as estuaries to spawn (Haffray et al., 2012) where they make loud choruses (Lagardère and Mariani, 2006). The advertisement calls produced during spawning aggregations include a continuous range of calls composed by 1 pulse up to ca. 100 pulses (Lagardère and Mariani, 2006; Vieira et al., 2020; Pereira et al., 2020). In this species, both adult males and females, and juveniles (with at least $30 \mathrm{~cm}$ ) produce calls (Pereira et al., 2020).

There is a high diversity of hearing structures in sciaenids and hearing sensitivity has been characterized in a few species (Ramcharitar et al., 2004; Horodysky et al., 2008; Codarin et al., 2009; Wysocki et al., 2009), but not in the meagre. Most species studied within the Sciaenidae family are fish with no special structures connecting the gas bladder to the inner ear, which usually enables a higher sensitivity to the pressure component of sound (Ramcharitar et al., 2006). To date, only Bairdiella chrysoura was recognized as a sciaenidae species highly sensitive to sound pressure (Ramcharitar et al., 2004; Popper and Fay, 2011). This species has a two-chamber swimbladder, with the anterior chamber surrounding the otic capsule and terminating lateral to the saccules, an arrangement that enhance hearing (Ramcharitar et al., 2006).

Here, using a highly vocal fish species, the meagre, we investigate the effects of boat noise both on hearing under laboratorial conditions and on the vocal responses of free ranging fish. Specifically we 1) use non-invasive auditory evoked potential (AEP) recordings to a) estimate the auditory thresholds of meagre juveniles to single frequency stimuli, b) characterize the hearing response to conspecific calls and c) evaluate to which extent boat noise can mask conspecific calls. Furthermore, we
2) use passive acoustic monitoring to assess changes in the vocal activity of chorusing adults to boat passages in the natural environment.

\section{Material and methods}

\subsection{Meagre hearing and boat masking effect}

\subsubsection{Experimental animals}

Meagre juveniles were obtained from the aquaculture facilities of Instituto Português do Mar e da Atmosfera - Estação Piloto de Piscicultura de Olhão (IPMA -EPPO) and transported to the laboratory at the University of Lisbon (Portugal). IPMA-EPPO has an authorization according to EU legislation to breed, use and supply aquatic animals for scientific experimental work provided by DGAV - the Portuguese National Authority for Animal Health - (DGAV reference 0421/000/000/ 2018). They were kept in $200 \mathrm{~L}$ stock tanks equipped with a cooler (Hailea HC300A), external filter (Eheim 150) and aeration, under a 12 h:12 h light:dark cycle, and fed twice a day with the same inert semimoist feeds used in the aquaculture facility. Water temperature was kept at $16+/-1{ }^{\circ} \mathrm{C}$. We used a total of 24 juvenile fish (sex undefined; 1 fish used in preliminary experiments; 13 fish to estimate the auditory thresholds; and another 10 fish to estimate detection threshold of conspecific calls with and without boat noise). Total length ranged from 10.7 to $13.3 \mathrm{~cm}(11.7 \pm 0.9 \mathrm{~cm}$; Mean $\pm \mathrm{SD})$. All experimental procedures comply with European animal welfare laws, guidelines and policies and were approved by the ethics body of the Faculty of Sciences (ORBEA statement 5/2018).

Juveniles were chosen due to setup and maintenance constraints that prevented the use of large fish. In this species maturity is only reached at ca. $50 \mathrm{~cm}$ in aquaculture conditions (Gil et al., 2013) and ca. $85 \mathrm{~cm}$ total length (TL) in the wild (Prista et al., 2014). Fish with the range of sizes used in this study do not produce sounds (Pereira et al., 2020).

\subsubsection{Experimental procedure}

The protocol for AEP recordings followed Kenyon et al. (1998), adapted by Wysocki and Ladich (Wysocki and Ladich, 2001; Wysocki and Ladich, 2003), and used by Alves et al. (2016). In short, each juvenile fish was mildly anesthetized with MS-222 (ethyl 3-aminobenzoate methanesulfonic acid salt, ACROS Organics, Geel, Belgium) to be immobilized in a soft sponge, with the opercula free but with the head movements restricted by pieces of plastic soft tubing in both sides of the snout and jaw. The experiments were initiated after no visible effect of the anesthetic was observable. The subjects were positioned in the centre of the experimental cylindrical tub (diameter $35 \mathrm{~cm}$, water depth $18 \mathrm{~cm}$ ) and just below the water surface, allowing fish to breathe normally. The saltwater temperature was at ca. $17+/-1{ }^{\circ} \mathrm{C}$. At the end of the experiments fish were lightly anesthetized, weighed and measured, allowed to recover from the anaesthesia in an aerated bucket and placed in a second tank.

AEPs are summed potentials of the nervous system electrical activity evoked by acoustic stimuli. To record the AEPs, a measuring electrode was positioned and slightly pressed on the skin of the mid upper surface of the head, above the brainstem, and the reference electrode was located on the skin close to the nostrils (Fig. 1). The AEPs were amplified (Grass CP511, Grass Instruments, USA, gain 20,000×, high-pass $10 \mathrm{~Hz}$, low-pass $1000 \mathrm{~Hz}$ ), digitized (Edirol UA25-EX Roland Corporation, Tokyo, Japan: $48 \mathrm{kHz}, 16 \mathrm{bit}$ ) and recorded to a PC running Adobe Audition 3.0 (Adobe Systems Inc., CA, USA).

Acoustic stimuli (see below) were fed via an Edirol UA-25EX to an amplifier and delivered through an underwater sound generating device (described in Vasconcelos et al., 2011 and in Alves et al., 2016). The sound pressure levels of the stimuli used were calibrated with a hydrophone (8104, Brüel \& Kjær, Naerum, Denmark; sensitivity -205 dB re. 1 $\mathrm{V} \mu \mathrm{Pa}^{-1}$; frequency response from $0.1 \mathrm{~Hz}$ to $180 \mathrm{kHz}$ ) positioned in the place later occupied by the fish inner ears and connected to a sound level meter (Bruël \& Kjaer 2238 Mediator, Naerum, Denmark). Particle 


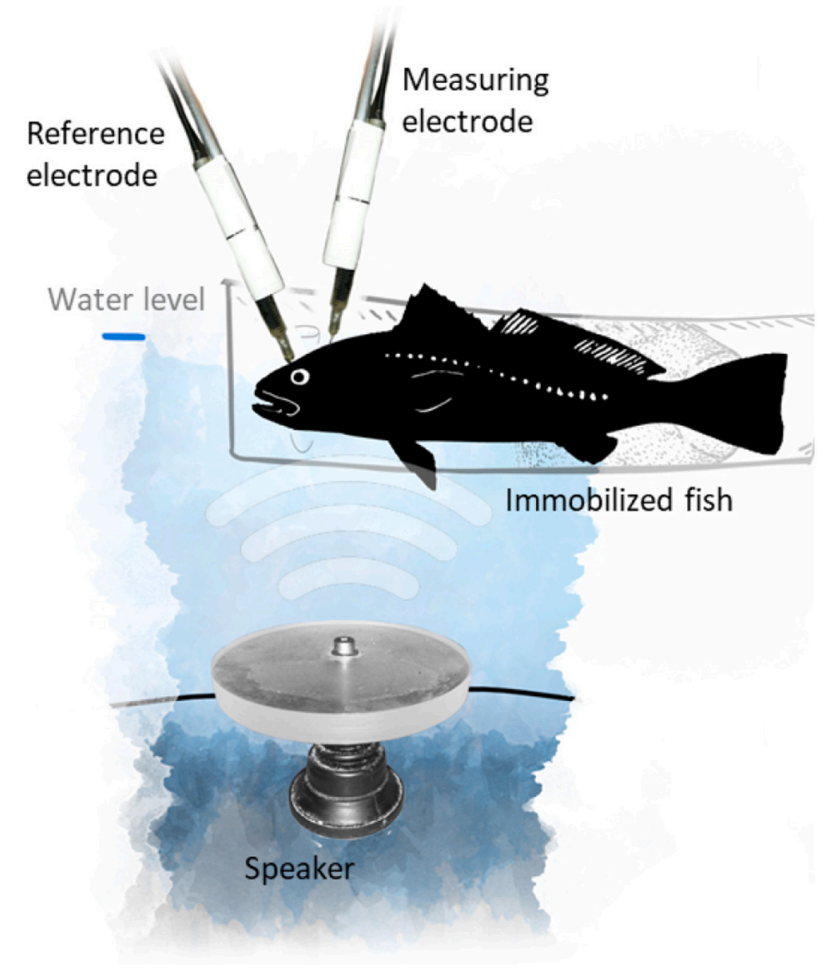

Fig. 1. The experimental setup for measuring the Auditory Evoked Potentials (AEPs). Test subjects were positioned just below the water surface. A measuring electrode was positioned at mid upper surface of the head, above the brainstem, and the reference electrode was located close to the nostrils. Acoustic stimuli were fed via an Edirol UA-25EX, amplified, and delivered through an underwater sound generating device.

motion patterns of the sound stimuli were measured with a 3-axis accelerometer (M20-040, sensitivity 0-3 kHz, GeoSpectrum Technologies, Dartmouth, Canada) and the same B\&K hydrophone and Mediator, both roughly positioned in the region of the tank later occupied by the fish earing structures. The outputs of both instruments (pressure and acceleration) were simultaneously logged using the same recording chain. The voltage of each channel used to record the 3 axis accelerometer outputs (xx, yy or $\mathrm{zz}$ ) was calibrated by recording sinusoidal waves at two pre-set amplitude voltages and at three different frequencies distributed in the range of the stimuli frequencies. Fig. S1 shows the acoustic characterization of the tank location occupied by the fish in this study.

\subsubsection{Sound stimuli}

2.1.3.1. Meagre audiogram. Acoustic stimuli consisted of single tone short sounds at frequencies of $30,45,60,85,100,120,165,200,245$, $300,400,500,705,800,1000$ and $2000 \mathrm{~Hz}$. These frequencies encompass the hearing range of other sciaenid species (Horodysky et al., 2008). Sound pressure levels were attenuated in 3-dB steps from 130 down to $85 \mathrm{~dB}$ re. $1 \mu \mathrm{Pa}$. Stimuli were presented in a random order. Each stimulus was presented 1000 times, half at opposite polarities (i.e., $2 \times$ 500 times $180^{\circ}$ phase shifted). Sounds stimuli at opposite polarities are used to eliminate eventual stimulus artefacts in the AEPs because the auditory responses are not affected by polarity changes (Wysocki and Ladich, 2003). Stimulus duration ranged from 4 cycles at $30 \mathrm{~Hz}$ (ca. 133 $\mathrm{ms}$ ) to 20 cycles at $2000 \mathrm{~Hz}(10 \mathrm{~ms})$. Stimulus interval was about the same as stimulus duration. Hearing thresholds were measured in 13 fish.

2.1.3.2. Sensitivity to conspecific calls. Short grunts with a high signalto-noise ratio from three fish with 6,7 and 8 pulses recorded from adult males reared at the aquaculture facilities of Instituto Português do Mar e da Atmosfera - Estacão Piloto de Piscicultura de Olhão (IPMAEPPO, Portugal, $37^{\circ} 02^{\prime} \mathrm{N}, 7^{\circ} 49^{\prime} \mathrm{W}$ ), were selected (see Fig. 2A). For playback they were adjusted to an amplitude of $120 \mathrm{~dB}$ re. $1 \mu \mathrm{Pa}$. Preliminary tests indicated that this sound level was well above the hearing threshold for short grunts. Playbacks were subsequently attenuated in 6 $\mathrm{dB}$ steps down to a subthreshold amplitude of $72 \mathrm{~dB}$ re. $1 \mu \mathrm{Pa}$. Each stimulus was presented 1000 times at opposite polarities, with intervals between presentations equal to $50 \%$ of the stimulus duration. Each fish under study was stimulated with one grunt file attributed in a random order. The response of 6 fish were studied.

2.1.3.3. Boat noise masking effect assessed through Auditory Evoked Potentials. To assess the masking effect of boat noise we selected noise from two boat types common in the Tagus estuary: two recordings of small open deck boats with an outboard engine, and two recordings of ferryboats (see Fig. 2B). These different boat noises, two of them used in a previous study (Alves et al., 2021), have different frequency components, thus likely causing different masking. We adjusted the amplitude of the boat noise playback to $130 \mathrm{~dB}$ re. $1 \mu \mathrm{Pa}$, corresponding to the noise amplitude of a ferry passing within $50-100 \mathrm{~m}$ from the hydrophone placed $1 \mathrm{~m}$ below the surface in a $5 \mathrm{~m}$ deep water location (measured at the pier where the sound recordings were made to evaluate the effect of boat passages on meagre chorus sound; see below). The boat noise file was then mixed with the aforementioned short grunts. These grunts were attenuated in $6 \mathrm{~dB}$ steps, from $127 \mathrm{~dB}$ down to $91 \mathrm{~dB}$ re. 1 $\mu \mathrm{Pa}$, prior to mixing with the constant $130 \mathrm{~dB}$ boat noise file. In the playback stimuli the grunt started $50 \mathrm{~ms}$ after the boat noise onset, that

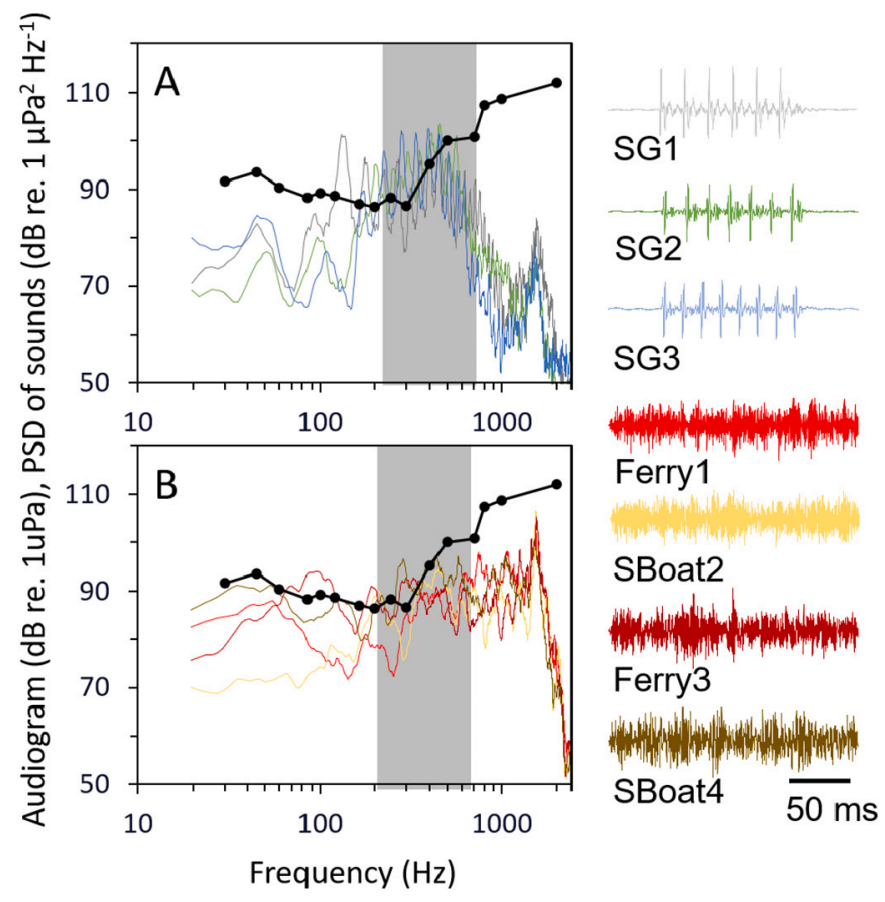

Fig. 2. Spectra and oscillograms representing the conspecific sounds and boat noises played back in the AEP experiments. (A) Power spectral density of short grunts (SG1, SG2, SG3) at $127 \mathrm{~dB}$ re. $1 \mu \mathrm{Pa}$. (B) Power spectral density of the boat noises at $130 \mathrm{~dB}$ re. $1 \mu \mathrm{Pa}$. Oscillograms represent the short grunts (SG1, SG2, SG3), the small fishing motorboats with an outboard engine (SBoat2, SBoat4) and the ferryboats (Ferry1, Ferry3). Comparison with a baseline audiogram is provided (black line); note, however, that for estimation of masking critical ratios the knowledge of critical bandwidths is needed (Erbe et al., 2016) but is unknown for this species. Oscillograms are colour coded according to the spectra depicted in the graphs. Shadowed sections represent the dominant frequencies of these meagre calls (Pereira et al., 2020). For comparison with original used recordings, see Fig. S5. 
lasted $240 \mathrm{~ms}$. Each stimulus was presented 1000 times at opposite polarities, with $60 \mathrm{~ms}$ intervals between presentations. Stimuli were attributed to fish in a random order. The response of 8 individuals were studied, some fish were exposed to several stimuli and one was excluded.

\subsubsection{AEP analysis}

The thresholds of the AEP responses to single tones were obtained by visual inspection of the waveform and spectra of the averaged AEPs recorded with decreasing stimuli amplitudes. The auditory threshold was defined as the lowest stimulus amplitude at which a visible AEP response was identified in the averaged waveform. This criterium has been widely used in fish hearing studies (Wang et al., 2015; Monroe et al., 2016; Breitzler et al., 2020).

To obtain the thresholds of the AEP response to conspecific calls (short grunt) without or with the presence of boat noise we adapted the protocol described by Vasconcelos et al. (2011) and Alves et al. (2016) to estimate the minimum stimulus amplitude at which each fish correctly represented the features of a short grunt without and with boat noise. In brief, we computed Pearson correlations between the averaged AEP response to the short grunt stimulus presented at the higher amplitude and the AEP responses to the same grunt recorded at the various decreasing amplitudes. The threshold was defined as the average plus twice the standard deviation of the values of the correlation coefficients with subthreshold stimuli in all the experimental trials. Waveform and power spectra of the averaged AEP responses were also computed as an additional method to interpret the AEP responses.

\subsubsection{Masking predictions}

As the call-to-noise ratio decreases, communication in the presence of background noise gets progressively harder (Fletcher, 1940). Fletcher (1940) introduced the power spectrum model of masking, which predicts that the detection threshold occurs when the SNR is null. However, the computations must take into account the bandwidth of the auditory filter. This can be estimated by the critical bandwidth, which is a measure of the auditory filter width at each centre frequency. The critical bandwidth can be determined in masking hearing experiments where the spectral width of the noise band is progressively increased until the detection threshold of a tone at the centre of the white noise is reached. In these experiments devised by Fletcher (1940), the masking threshold value increases as the bandwidth of the noise is widened until the bandwidth of the noise equals the bandwidth of the auditory filter. After that, the masking threshold will remain constant, even if the noise bandwidth is widened. Note that even when the noise bandwidth is widened, the sound pressure level per band is maintained. The critical bandwidth is the noise bandwidth where the plateau of the masking threshold is observed.

Notice that the sound pressure level of a single sound frequency, usually used for the estimation of a frequency threshold in an audiogram, can only be compared with the surrounding noise power spectral density level if the critical bandwidth, or the critical ratio, is taken into account (Erbe et al., 2016). This approach has been used to predict masking noise levels for several species (e.g., Erbe and Farmer, 2000; Jensen et al., 2009; Putland et al., 2017; Stanley et al., 2017). In cases of birds and marine mammals where the relevant bandwidth was not known, one-third octave bands were commonly used (Dooling et al., 2015; Erbe et al., 2016). In the present study, we tested the one-third octave bandwidths as an approximation to the critical bandwidth of fish. Here, we estimated the detection thresholds of the conspecific signals (grunts) applied in the AEP experiments under baseline and boat noise conditions, using one-third octave band levels centred at 250, 315, 400 and $500 \mathrm{~Hz}$.

\subsection{Fish vocal behaviour patterns}

\subsubsection{Passive acoustic monitoring setup}

To investigate the boat noise impact on meagre calling activity we used sound recordings obtained in Tagus estuary (Air Force Base 6, Montijo, Portugal; $38^{\circ} 42^{\prime} \mathrm{N}, 8^{\circ} 58^{\prime} \mathrm{W}$ ). The data set consisted of ca. 30 day round-the-clock recordings from April and May 2018. The High Tech 94 SSQ hydrophone (sensitivity - $165 \mathrm{~dB}$ re. $1 \mathrm{~V} / \mu \mathrm{Pa}$, flat frequency response up to $6 \mathrm{kHz} \pm 1 \mathrm{~dB}$ ) was deployed in a pier and anchored at about $20 \mathrm{~cm}$ from the bottom to a stainless-steel holder projecting from a concrete base where the cable was attached to minimise current-induced hydrodynamic noise. Sound was continuously recorded to a stand-alone 16 channel datalogger (LGR-5325, Measurement Computing Corp, Norton, MA, USA; $4 \mathrm{kHz}$ sampling rate, $16 \mathrm{bit}$ ). Depth at the deployment spot ranged from ca. 2.5 to $6 \mathrm{~m}$, depending on tide. Meagre choruses are commonly recorded in this place (Pereira et al., 2020). Boat passages usually occurred from 6 a.m. to midnight (Vieira et al., 2019).

\subsubsection{Automatic recognition of meagre vocalizations and boat passages}

To detect and identify the sounds on the recordings we used two automatic recognition systems: (system-1) for boat noise recognition (as described by Vieira et al., 2019); and (system-2) for meagre chorus identification (adapted from Vieira et al., 2020). In short, multiple hidden Markov models HMMs were trained using sounds of each defined category, and then used to classify the recordings according to the highest likelihood.

2.2.2.1. Signal processing. Firstly, the signal waveform is subdivided into a sequence of elementary segments, according to a predefined window duration (Fig. S2, cf. Fig. 1 in Vieira et al., 2015). We used the following acoustic features: cepstrum, Mel-frequency cepstral (MFC), delta, and acceleration coefficients. Different windows and frequency bandwidths were used in each system. System 1 - boat noise recognition: $200 \mathrm{~ms}$ window with a $50 \%$ overlap, frequency bandwidth of 1200-2000 Hz; System 2 - meagre chorus recognition: 32 ms window with a $50 \%$ overlap, frequency bandwidth of $20-2000 \mathrm{~Hz}$. A Hamming window was applied to each frame in both cases. The MFCC used a 26filter bank and only the first 12 cepstral coefficients were selected.

2.2.2.2. HMM time alignment. For the boat noise recognition (system 1), we created a 224-state model to classify the noise of small boats passages and ferryboats passages. As in Vieira et al. (2019), we added models with 5 states for modelling background noise (silence), and models with 224 states for non-biological sound patterns with intermediate energy and long duration (e.g. unknown anthropogenic noise from stationary sources). These additional states were crucial to avoid misclassification.

For the meagre chorus recognition (system 2), we created a 50-state model to classify and discriminate a) choruses dominated by pulses (calls with 1 to 3 pulses), b) choruses dominated by longer calls (mostly long grunts) with low rate of overlap, c) choruses dominated by long grunts with high rate of overlap, forming a mostly continuous roar, and d) choruses dominated by pulses and long grunts (usually with an intermediate rate of overlap; Fig. S3). Furthermore, we added a 14-state model to recognize long grunts with a high signal-to-noise ratio. This recognition system was trained to identify segments of choruses because most calls overlap other calls and, in many cases, it is not possible to discriminate the beginning and the end of each call. As in Vieira et al. (2019), we added models with 5 states for modelling background noise (silence; same as in system 1), and non-biological sound patterns with high energy and short duration (e.g., consecutive non-biological pulses with high energy possible related to self-noise and breaking waves). Models with 14 states for modelling toadfish (Halobatrachus didactylus) boatwhistles, double-croaks and grunt trains in the absence of meagre calls were also added as toadfish sounds are also common in the recording site (Vieira et al., 2021). 
For each model, a representative subset of samples was used to train the HMMs (see below). The transition probabilities and the elementary segment probability densities of each state were estimated with the Baum-Welch algorithm (Baum et al., 1970). The training set used to produce the boat noise recognition system included 80 ferryboat passages, 16 small boat passages and 97 sounds for the other models. The training set for the meagre chorus recognition system included 323 files with different meagre choruses including several observed variations (multistyle training) and 700 sounds for the other models (165 silence, 19 boat noise, 25 other non-biological sounds, 19 boatwhistles, 141 double-croaks and 331 toadfish's grunt trains). Note that initially we assigned at least 15 sounds to each model. After several preliminary tests (using a different dataset from the one used to evaluate the system), we included additional sounds, specially in the most common and intravariable sound classes. Since several toadfish double-croaks and toadfish grunt trains were initially wrongly assigned as meagre sounds, we added several of these wrongly assigned sounds into the dataset used to train these models, which resulted in an improvement in sound identification rate and accuracy.

In the recognition phase, each sound type was matched against the estimated HMM for each sound type. This was achieved by using a Viterbi algorithm (Forney, 1973) that produced a likelihood measure for each HMM.

For computations we used the HMM Toolkit (HTK, University of Cambridge, UK), a group of modules written in $\mathrm{C}$ to create automatic recognition systems for human speech (Young et al., 2006).

2.2.2.3. Evaluation of the recognition system. Each automatic HMMbased recognition system was prepared to recognize the pre-defined sounds, considering the existence of the other sounds, i.e., sounds produced by other species and/or other abiotic noises.

The boat passage recognition system was previously evaluated by Vieira et al. (2019) using a subset of 4 days (both identification rate and accuracy of $90.9 \%)$.

To evaluate the output of the meagre sounds recognition system, its identification rate and accuracy were assessed by comparison with manually annotated data on a subsample of ca. $180 \mathrm{~min}$. Due to the continuous nature of the chorus, the identification rate and accuracy of the system to recognize choruses was evaluated taking into account the number of seconds correctly recognized, instead of the number of events. The overall identification rate reached $97.4 \%$, and the accuracy was $96.7 \%$. In detail, the identification rate and accuracy were: $100 \%$ and $94.6 \%$ for individual long grunts; $77.1 \%$ and $76.0 \%$ for choruses dominated by pulses; $99.8 \%$ and $98.0 \%$ for choruses with low rate of overlap; $94.1 \%$ (and same accuracy) for choruses with high rate of overlap; and $98.2 \%$ (and same accuracy) for choruses dominated by pulses and long grunts.

\subsubsection{Data analysis}

The computations using the sound labels and all statistics were performed in R (R Core Team, 2018).

Using the labels produced by the automatic recognition system, we calculated the average root mean square sound pressure level (SPL) on the recordings corresponding to each boat passage, in the presence or absence of meagre chorus. SPL was calculated for two frequency bandwidths: (1) the bandwidth dominated by the meagre calls $(300-600 \mathrm{~Hz})$ and (2) a bandwidth essentially dominated by anthropogenic noise (1700-2000 Hz). The SPL was averaged for each $10 \mathrm{~s}$. We considered $100 \mathrm{~s}$ before and $250 \mathrm{~s}$ after the start-time indicated by the label of the boat recognition system. SPL was rescaled to start from zero at each considered section. Every boat passage was aligned and averaged considering the start-time labelled by the automatic recognition system, approximately corresponding to the section where boat noise energy can be visually detected on a spectrogram. Only ferryboat passages were considered. The timestamps of boat passages and meagre choruses were defined by the automatic recognition systems.

To understand if the mean meagre chorus SPL variation during the boat passages was significantly different from what could be expected by chance, a block bootstrap method was performed (Hinkley, 1988; see scheme in Fig. S4). One hundred simulations were made using samples generated following 3 steps: 1) random selection of a start-time, i.e. random selection of sections equivalent to boat passages, 2) measurement of the mean SPL for every $10 \mathrm{~s}$ in a block of $350 \mathrm{~s}, 3$ ) every section on every random selection was aligned and averaged ( $n$ equal to the number of boat passages previously assessed). In the end, the means of the one hundred simulations were summarized for every $10 \mathrm{~s}$ in the block of $350 \mathrm{~s}$. The SPL range observed on these simulations represent what should be expected if the SPL variations observed during each boat passage were caused by chance. Note that through visually inspection of spectrograms of the meagre chorus, there are other moments not related with boat passages where a change of SPL is observed.

\section{Results}

\subsection{Meagre hearing and boat masking effect}

\subsubsection{Meagre audiogram}

The meagre presented the best hearing sensitivity at $300 \mathrm{~Hz}$ both in sound pressure and particle motion (ca. $86 \mathrm{~dB}$ re. $1 \mu \mathrm{Pa} ;-67 \mathrm{~dB}$ re. 1 $\mathrm{ms}^{-2}$ ), although it showed a good sensitivity in the frequency range 30-300 Hz (Figs. 2 and 3, Table S1). At higher frequencies the hearing sensitivity steadily decreased, even though the calls produced by this species can present peak frequencies ranging between below 300 up to $600 \mathrm{~Hz}$ (Fig. 2A). The audiograms expressed in terms of sound pressure and particle motion were very similar (Fig. 3, Table S1). Note that we only represented the vertical component (z-axis) of particle acceleration because it had substantially larger amplitudes than the two horizontal components (axes $\mathrm{x}$ and $\mathrm{y}$ ). As reported in other studies (e.g. Horodysky et al., 2008), an attenuation of the sound pressure level resulted in a similar decrease on particle acceleration in all three axes.

\subsubsection{Conspecific calls and boat noise representation in the Auditory Evoked Potentials}

The temporal structure of conspecific calls, i.e. sound duration and pulse period, was accurately represented in the auditory response of several individuals $(n=6$, examples in Fig. 4A). However, the pulses detailed structure was not accurately represented within each grunt. Boat noise was also represented in the AEPs, although only lower

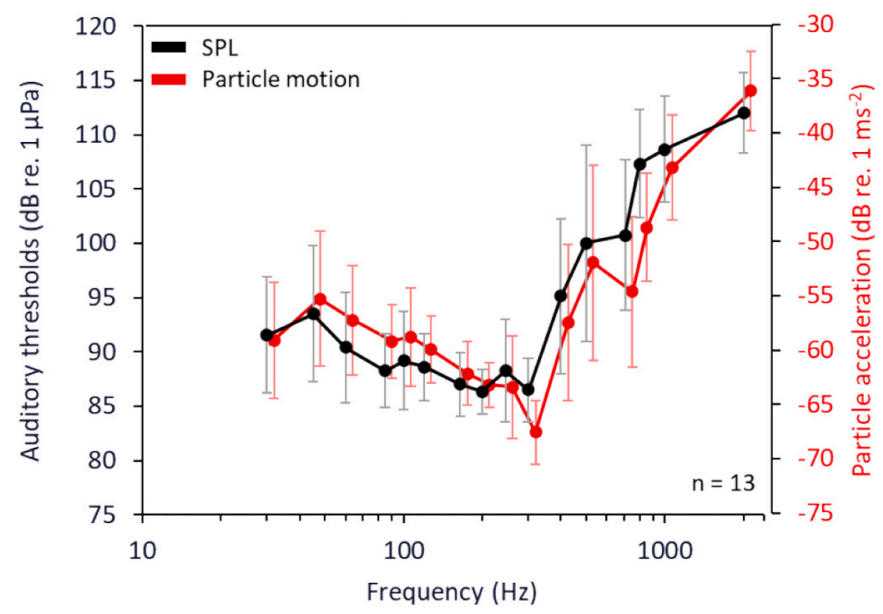

Fig. 3. Audiogram of juvenile meagre in sound pressure level (SPL, dB re. 1 $\mu \mathrm{Pa}$, black line) and acceleration in the z-axis ( $\mathrm{dB}$ re. $1 \mathrm{~ms}^{-2}$, red line). (For interpretation of the references to colour in this figure legend, the reader is referred to the web version of this article.) 
A

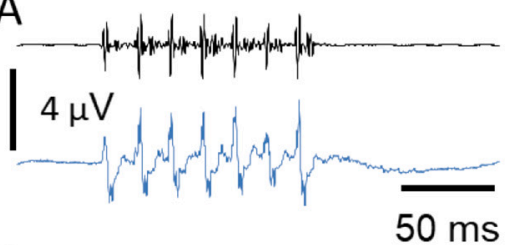

$\mathrm{A}_{1}$

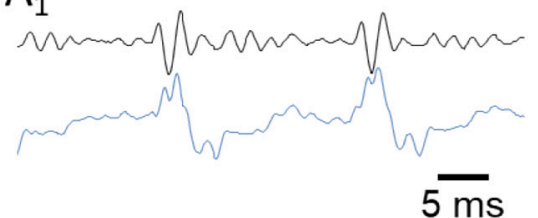

C

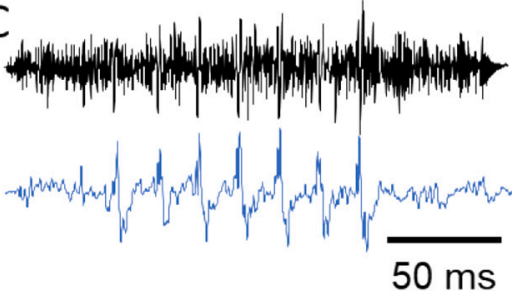

$\mathrm{C}_{1}$

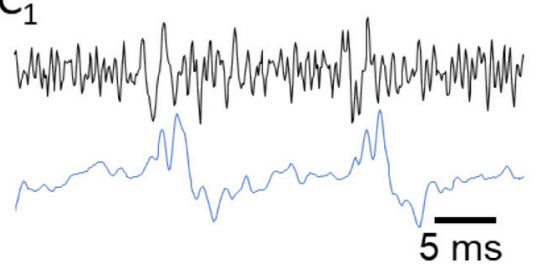

B

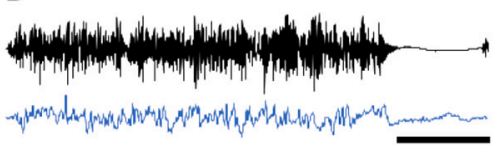

$50 \mathrm{~ms}$

$\mathrm{B}_{1}$

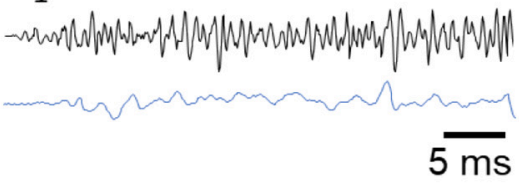

D
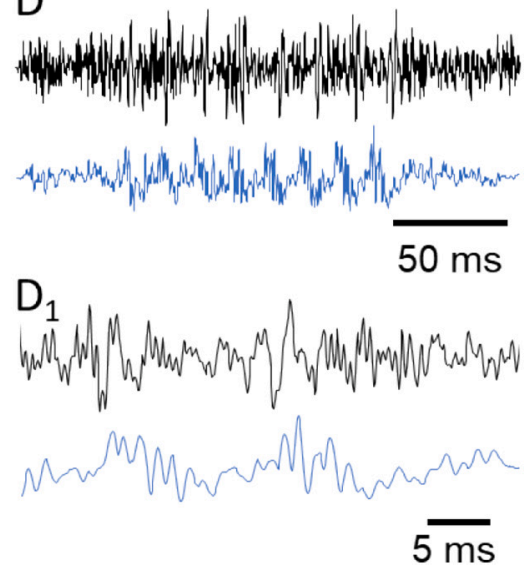

Fig. 4. Oscillograms of several sound stimuli (upper black trace) and corresponding auditory evoked response examples (lower blue trace) recorded from meagre juveniles. Sound stimuli shown consist of: (A) conspecific short grunt with 7 pulses at $127 \mathrm{~dB}$ re. 1 $\mu \mathrm{Pa}$; (A1) detail of (A); (B) Ferryboat noise at $130 \mathrm{~dB}$ re. $1 \mu \mathrm{Pa}$; (B1) detail of (B); (C) conspecific short grunt represented in (A) mixed with ferryboat noise at $130 \mathrm{~dB}$ re. $1 \mu \mathrm{Pa}$; (C1) detail of (C); (D) conspecific short grunt mixed with small boat noise at $130 \mathrm{~dB}$ re. $1 \mu \mathrm{Pa}$; (D1) detail of (D). (For interpretation of the references to colour in this figure legend, the reader is referred to the web version of this article.) frequencies were well represented (Fig. 4B; lower than ca. $400 \mathrm{~Hz}$ ). The short grunt at $127 \mathrm{~dB}$ re. $1 \mu \mathrm{Pa}$ mixed with boat noise at $130 \mathrm{~dB}$ re. $1 \mu \mathrm{Pa}$ (overall SPL) elicited pulsed AEPs with a shape similar to the ones observed with no-noise (Fig. 4C1 vs. 4A1), suggesting that the temporal pattern information of grunts is retained even under considerable boat noise exposure. Note, however, that there is some variability, for example in Fig. 4D1 the presence of grunt pulses is still noticeable but concealed by higher frequency noise from the boat sound. Each fish presented different pulse shapes in the AEP responses that may be due to individual differences, subtle changes on the relative position of the electrodes or differences in the electrical contact between electrode and fish tissues/tank water.

\subsubsection{Sensitivity to conspecific calls}

Using Pearson correlation coefficients between the averaged AEP at each stimulus amplitude and the AEP at the higher stimulus amplitude, the estimated detection thresholds for the conspecific short grunt calls ranged on the 6 tested fish from 84 to $108 \mathrm{~dB}$ re. $1 \mu \mathrm{Pa}$, with a mean of

\section{Table 1}

Estimated detection threshold ( $\mathrm{dB}$ re. $1 \mu \mathrm{Pa}$ ) and predicted detection thresholds ( $\mathrm{dB}$ re. $1 \mu \mathrm{Pa}$ ) using AEPs recordings and the power spectrum model of masking, respectively. AEPs detection thresholds were estimated using Pearson correlations between the averaged AEP response to the short grunt stimulus presented at the higher amplitude and the AEP responses to the same grunt recorded at the various decreasing amplitudes. Prediction using the power spectrum model of masking considered a critical bandwidth of one-third octave. Represented predicted values are the mean, minimum (most of the signal is still above the noise) and maximum (all the signal is just below the noise) of the four values obtained from the third octave bands centred on the 250,315, 400 and $500 \mathrm{~Hz}$.

\begin{tabular}{|c|c|c|c|c|c|c|c|c|c|c|c|c|c|c|c|}
\hline & \multicolumn{5}{|c|}{ No noise } & \multicolumn{5}{|c|}{ Small boat noise } & \multicolumn{5}{|c|}{ Ferry boat noise } \\
\hline & \multirow{2}{*}{$\begin{array}{l}\text { Fish } \\
\text { ID }\end{array}$} & \multirow{2}{*}{$\begin{array}{l}\text { Detection } \\
\text { threshold }\end{array}$} & \multicolumn{3}{|c|}{ Prediction } & \multirow{2}{*}{$\begin{array}{l}\text { Fish } \\
\text { ID }\end{array}$} & \multirow{2}{*}{$\begin{array}{l}\text { Detection } \\
\text { threshold }\end{array}$} & \multicolumn{3}{|c|}{ Prediction } & \multirow{2}{*}{$\begin{array}{l}\text { Fish } \\
\text { ID }\end{array}$} & \multirow{2}{*}{$\begin{array}{l}\text { Detection } \\
\text { threshold }\end{array}$} & \multicolumn{3}{|c|}{ Prediction } \\
\hline & & & mean & $\min$ & $\max$ & & & mean & $\min$ & $\max$ & & & mean & $\min$ & $\max$ \\
\hline & $16^{s g 2}$ & 102 & & & & $\begin{array}{l}21 \\
s g 1 b 2\end{array}$ & 121 & & & & $16^{\text {sg2f1 }}$ & 121 & & & \\
\hline & $17^{s g 3}$ & 96 & 99 & 106 & 93 & $\begin{array}{l}22 \\
s g 1 b 2\end{array}$ & 115 & & & & $\begin{array}{l}20 \\
s g 3 f 3\end{array}$ & 121 & 118 & 120 & 116 \\
\hline & $20^{s 93}$ & 90 & & & & $\begin{array}{l}23 \\
s g 3 b 4\end{array}$ & 121 & & & & & & & & \\
\hline & $21^{s g 1}$ & 84 & 97 & 103 & 93 & $\begin{array}{l}24 \\
s g 3 b 4\end{array}$ & 127 & & & & & & & & \\
\hline $\begin{array}{l}\text { Mean } \\
\quad \pm S D\end{array}$ & & $96.0 \pm 8.5$ & 99.0 & 104.5 & 94.3 & & $\begin{array}{l}120.0 \\
\pm 4.5\end{array}$ & 122.5 & 125.5 & 118.5 & & $\begin{array}{l}119.5 \\
\pm 3.0\end{array}$ & 116.5 & 119.0 & 112.5 \\
\hline
\end{tabular}

sg1, sg2, sg3 - short grunts stimuli. b2, b4 - small boat noise stimuli from boats 2 and 4 respectively. f3, f4 - ferryboat noise stimuli from ferryboats 3 and 4 respectively. 
$96.0 \pm 8.5 \mathrm{~dB}$ re. $1 \mu \mathrm{Pa}$ (Table 1 ). In each tested fish, the power spectra of AEP responses to conspecific calls decreased to background noise levels at about the stimulus amplitude corresponding to the AEPestimated detection threshold (e.g. for fish no. 20 both estimations led to a threshold of $90 \mathrm{~dB}$ re. $1 \mu \mathrm{Pa}$, Fig. 5). Yet, the threshold was usually easier to recognize through visual inspection of the averaged AEP waveform due to the pulsated nature of the short grunts (Fig. 5D). As expected, the average AEP power spectra maxima occurred at higher frequencies then the maximum of the grunt energy, possibly reflecting the double frequency effect of the evoked potentials. Note that evaluating the Pearson correlation coefficients as represented in Fig. 6, points to ca. $90 \mathrm{~dB}$ re. $1 \mu \mathrm{Pa}$ as the overall threshold for grunts. The high variability observed in Fig. 6 is concurrent with the variability observed in the visual inspection of the waveforms and spectra of the averaged AEPs.

\subsubsection{Boat noise masking effect assessed through the Auditory Evoked Potentials}

Short grunts from three fish were used to test the effect of boat noise in impairing the meagre capabilities for discriminating conspecific advertisement calls. This was assessed by evaluating the representation of the short grunt on the averaged AEP response to stimuli composed of short grunts mixed with boat noise. Table 1 and Fig. 6 summarize the effect of boat noise on the AEPs response to conspecific calls. Different boat noises appear to affect the auditory response similarly. A difference of ca. $20 \mathrm{~dB}$ in the estimated detection thresholds (Table 1, Fig. 6). Comparing the differences with and without boat noise observed through visual inspection of the waveform of the averaged AEPs response, a similar masking effect might be inferred (Fig. 7), despite the variability found among individual fish.

\subsubsection{Masking predictions}

Superimposing the meagre average audiogram to the one-third octave bands spectra of short grunts stimuli (Fig. 8A, B, C; compare black vs. grey, green and blue lines), we can infer that the detection threshold of short grunts might be just above $90 \mathrm{~dB}$ re. $1 \mu \mathrm{Pa}$. Note that most energy of the short grunts is about $200-700 \mathrm{~Hz}$ (grey area in the same figures) and that, within this range, the audiogram is very close (Fig. 8A, B) or just above (Fig. 8C) the $91 \mathrm{~dB}$ short grunt spectrum. This is in agreement with the estimations in Section 3.1.3. Table 1 shows the

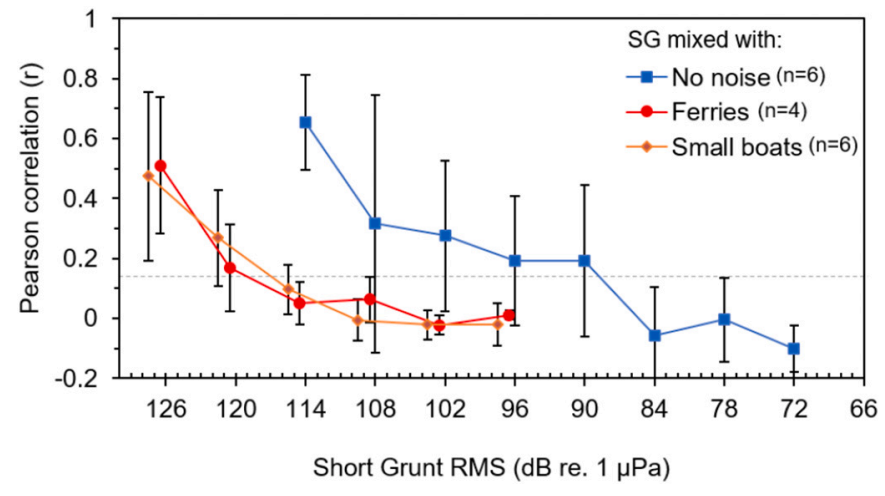

Fig. 6. Evaluation of the meagre's auditory response to the sound stimulus. If a fish detects a short grunt (SG), it is expected that its AEP response would be correlated with the clear AEP response to the same signal at high intensity. Therefore, Pearson correlations were carried out between the AEP response to a short grunt at highest amplitude and the AEP responses to the same short grunt embedded or not embedded in boat noise. The presence in the AEP of a response to the short grunt was considered when the Pearson correlation coefficient was above ca. 0.12 (threshold represented by the stippled line). This threshold was derived from the correlation values calculated for the AEP response with a short grunt stimulus at a subthreshold amplitude of $72 \mathrm{~dB}$ re. 1 $\mu \mathrm{Pa}$ (threshold $=$ average $+2 \times$ standard deviation). On the no noise experiments a short grunt at $120 \mathrm{~dB}$ re. $1 \mu \mathrm{Pa}$ was used as reference. On the experiments with boat noise, a short grunt at $127 \mathrm{~dB}$ re. $1 \mu \mathrm{Pa}$ without added background noise was used.

predictions based on the power spectrum model of masking considering a critical bandwidth of one-third octave. Additionally, we also tested the use of $1 / 1$ and $1 / 12$ octave bands. One octave bands also produced acceptable predictions, but $1 / 12$ octave bands tended to overestimate the detection thresholds (Fig. S6 and Table S2).

Furthermore, notice that just by comparing the PSD plots of short grunt stimuli (Fig. 2A) and boat noise (Fig. 2B) it is difficult to infer the possible masking effects caused by boat noise due in part to the absence of critical ratio information for this species. Nevertheless, based on the power spectrum model of masking and admitting one-third octave bandwidths to predict the masking effect of the boat noise, we can infer that the detection threshold under noise conditions might be closer to

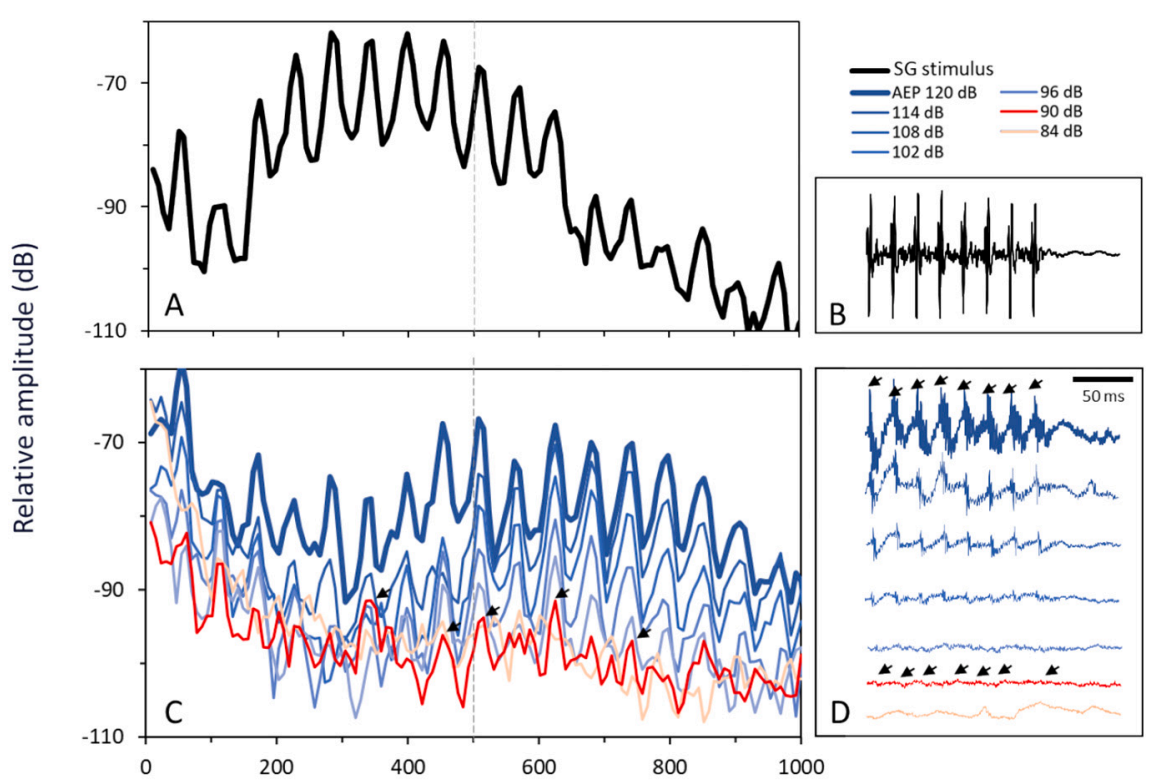

Fig. 5. Power spectra and oscillograms of averaged AEP responses (fish no. 20) to conspecific short grunts (SG) without noise. (A, B) Power spectrum and oscillogram of the acoustic signal; (C, D) Power spectra and oscillograms of the AEP responses to conspecific calls (attenuated in 6 $\mathrm{dB}$ steps, from $120 \mathrm{~dB}$ re. $1 \mu \mathrm{Pa}$; red line corresponds to threshold at $90 \mathrm{~dB}$; see Table 1). Spectra configuration: Sampling frequency, $8 \mathrm{kHz}$; FFT size, 1024; window type, Hanning; overlap samples per frame, 50\%. Arrows indicate the visible response to SG. Note that the response to a stimulus at $90 \mathrm{~dB}$ still has clear peaks at several frequencies (arrows in C) and response to SG pulses (arrows in D), while no such peaks are observed in the response to a stimulus at $84 \mathrm{~dB}$. (For interpretation of the references to colour in this figure legend, the reader is referred to the web version of this article.) 

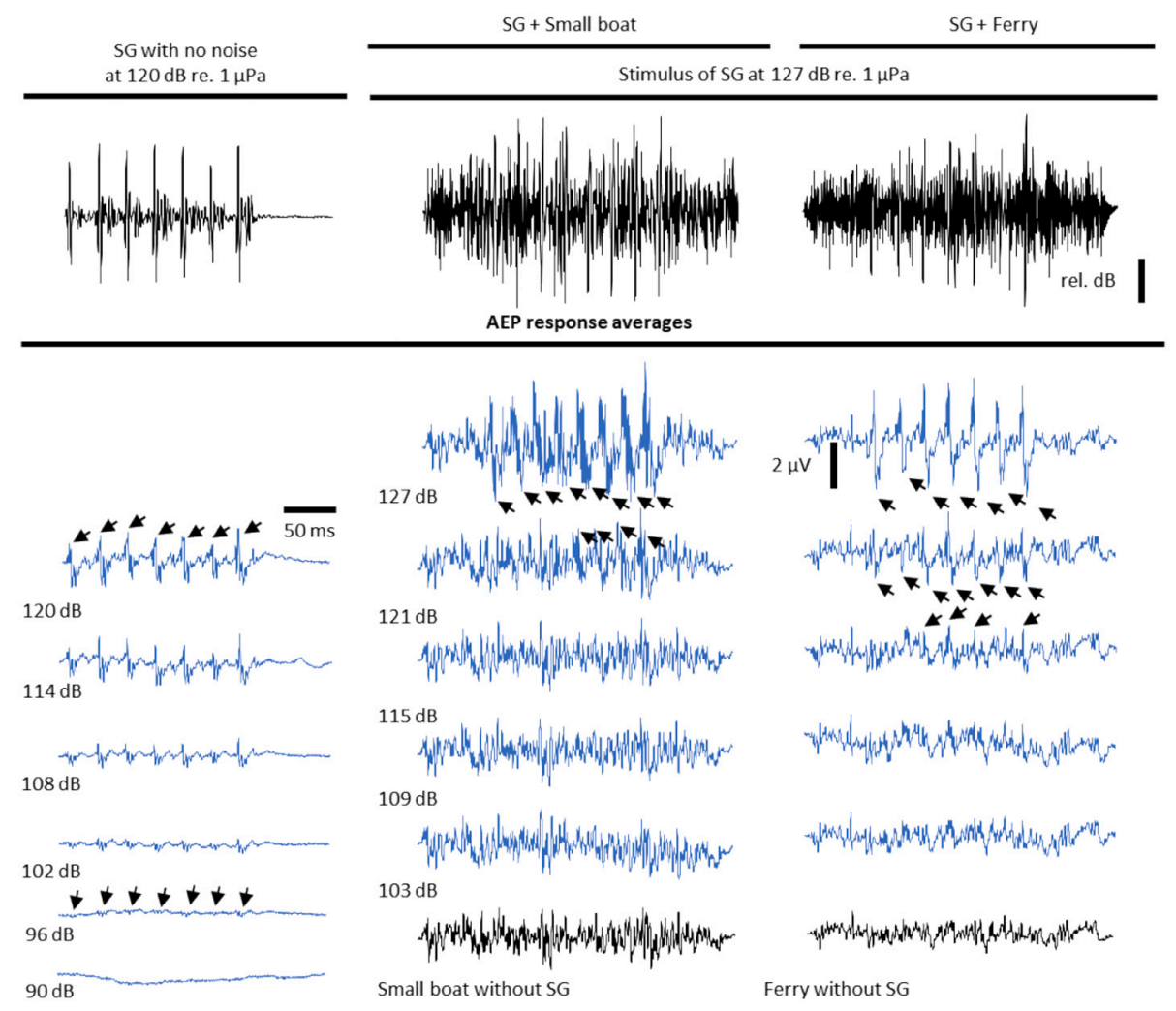

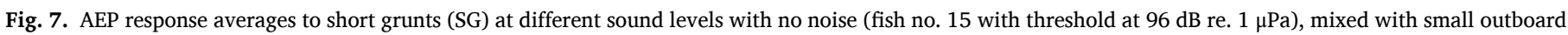

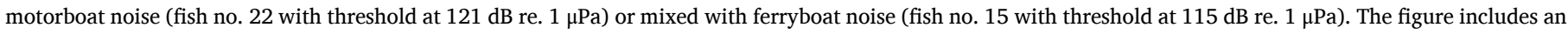
oscillogram of the SG stimulus mixed with small motorboat noise and with ferryboat. Arrows highlight the presence short grunt pulses.

$120 \mathrm{~dB}$ re. $1 \mu \mathrm{Pa}$ (Fig. 8A, B, C; compare boat noise spectra with grunt spectra and note that the boat noise spectra are close to 115 and $121 \mathrm{~dB}$ grunts spectra in $8 \mathrm{~A}$ and $8 \mathrm{C}$ ).

Table 1 also shows the detection thresholds predicted for each pair of signal and noise stimuli used in our experiments, based on the power spectrum model of masking and considering a critical bandwidth of onethird octave. Because the signals used are complex and it is unknown how much spectral information fish need to perceive a sound, we presented the thresholds considering the mean, maximum and minimum of the four values obtained from the one-third octave band levels centred on 250, 315, 400 and $500 \mathrm{~Hz}$. In the absence of boat noise, we compared the signal to the audiogram. At baseline conditions (no boat noise), the predicted detection threshold of grunt ranged from 93 to $106 \mathrm{~dB}$ re. 1 $\mu \mathrm{Pa}$. With additional small boat noise, the predictions ranged between 115 and $128 \mathrm{~dB}$ re. $1 \mu \mathrm{Pa}$, and with ferryboat noise ranged from 109 to $120 \mathrm{~dB}$ re. $1 \mu \mathrm{Pa}$.

\subsection{Fish vocal behaviour patterns}

Fig. 9 shows two examples of the effect of boat passages on the meagre chorus. Usually, a boat passage caused a decrease in the sound level of the meagre chorus and, in some cases, there was an interruption of the calling activity (Fig. 9B). On average, there was a decrease of ca. $1.25 \mathrm{~dB}$ in the $300-600 \mathrm{~Hz}$ frequency band on sections of recordings of meagre choruses with ferryboat passages (Fig. 10). This is a reduction relative to what would be expected in a random selection of sections with meagre chorus (light grey shadowed area in Fig. 10, see methods). Note, however, that ferryboats also produce energy on the meagre chorus frequency bandwidth (300-600 Hz; Fig. 10C), i.e. to obtain the overall effect on the chorus SPL one could add the increase in energy caused by the boat noise to the decrease in energy of the meagre chorus (simplified computation represented as dotted line in Fig. 10D). This means that, during the ferryboat passages, the energy of the meagre chorus decreases more than the energy of the ferryboat noise can compensate for.

\section{Discussion}

Several negative effects of noise on aquatic organisms have been described, including lowering attack rate of predatory fish (Purser and Radford, 2011; Hanache et al., 2020), reducing anti-predator behaviour (Simpson et al., 2015), altering movement patterns (Becker et al., 2013; Sarà et al., 2007), changing social behaviour (Bruintjes and Radford, 2013; Sebastianutto et al., 2011) and impacting spawning (de Jong et al., 2018; Blom et al., 2019). However, an insight of the effects of manmade noise into the behavioural responses and into the impacts on reproduction of wild fish is lacking (Shannon et al., 2015; Slabbekoorn, 2019; de Jong et al., 2020). Moreover, detrimental effects of anthropogenic noise have often been assessed through alterations of auditory thresholds (e.g. Vasconcelos et al., 2007; Codarin et al., 2009) but the impact on the detection of conspecific calls have only been evaluated in a couple of fish species (Codarin et al., 2009; Alves et al., 2021). In this study, we evaluated how noise can impact meagres' detection of conspecific mating calls and its effect on chorusing behaviour in freeranging fish. To achieve these goals, we (1) characterized the hearing response and assessed the impact of anthropogenic noise by comparing the representation of the conspecific calls in the AEP response of meagre juveniles before and after embedding the calls in boat noise, and (2) acoustically monitored the chorusing behaviour of meagre exposed to boat noise in the Tagus estuary. Our results indicate that boat noise can mask conspecific calls and may interfere with the chorusing behaviour during boat passages. 


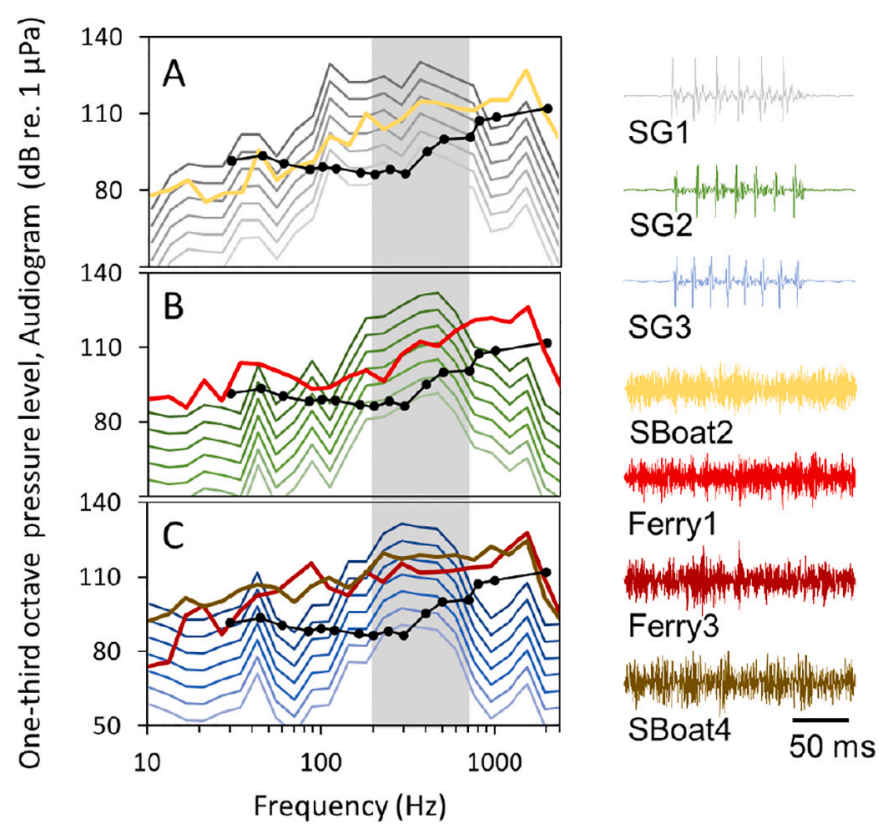

Fig. 8. One-third octave spectra (left panel) representing the pair of stimuli used during the AEP experiments on masking of conspecific calls by boat noise: short grunts attenuated in $6 \mathrm{~dB}$ steps, from $127 \mathrm{~dB}$ down to $91 \mathrm{~dB}$ re. $1 \mu \mathrm{Pa}$; and boat noise at $130 \mathrm{~dB}$ re. $1 \mu \mathrm{Pa}$. Right panel shows oscillograms representing the short grunts (SG1, SG2, SG3), noise from small fishing motorboats with an outboard engine (SBoat2, SBoat4) and noise from the ferryboats (Ferry1, Ferry3). Oscillograms are colour coded according to the spectra depicted in the graphs: (A) depicts SG1 and SBoat2; (B) SG2 and Ferry1; and (C) SG3, Ferry3 and SBoat4. Black lines represent the baseline meagre audiogram. Shadowed sections represent the dominant frequencies of these meagre calls (Pereira et al., 2020).

\subsection{Meagre hearing and boat masking effect}

\subsubsection{Meagre audiogram}

Within the Sciaenidae family, species can be classified on different classes in the "specialists" and "generalists" continuum (Ramcharitar et al., 2004; Horodysky et al., 2008; Wysocki et al., 2009), concurrent with the high diversity both of call production mechanisms and sound detecting structures. Indeed, sciaenids span a continuum within the extremes of the spectrum of fish auditory capabilities (Ramcharitar et al., 2006). In our study, the meagre showed high sensitivity below $300 \mathrm{~Hz}$, close to the reported values for the highly sensitive $B$. chrysoura, considered a "specialist" by Ramcharitar et al. (2004). At higher frequencies our data on juveniles are closer to the hearing performance reported for most fish of this family (Fig. 11; Horodysky et al., 2008; Wysocki et al., 2009). The $300 \mathrm{~Hz}$ higher sensitivity matches the usual peak frequency of sounds made by this species (Pereira et al., 2020). Most studied sciaenids present similar audiogram shapes but appear to be less sensitive (Fig. 11). Note, however, that hearing sensitivity reported here for juveniles could change in adult meagre as observed in some species (e.g. Stegastes partitus, Kenyon, 1996; Trichopsis vittata, Wysocki and Ladich, 2001; Porichthys notatus, Sisneros and Bass, 2005; and $H$. didactylus, Vasconcelos and Ladich, 2008), though in other fish species ontogenetic changes do not occur (e.g. Carassius auratus, Popper, 1971; Danio rerio, Higgs et al., 2002; and Abudefduf saxatilis, Egner and Mann, 2005). To our knowledge, no study has been undertaken on the ontogenetic changes of auditory sensitivity on sciaenids. Nevertheless, otolith morphology changes and relative sensory area increases during ontogeny in the closely related Argyrosomus japonicus (Taylor et al., 2020), suggesting ontogenetic variations in the hearing abilities, but likely an improvement.

One should be aware, however, that differences in the methodology
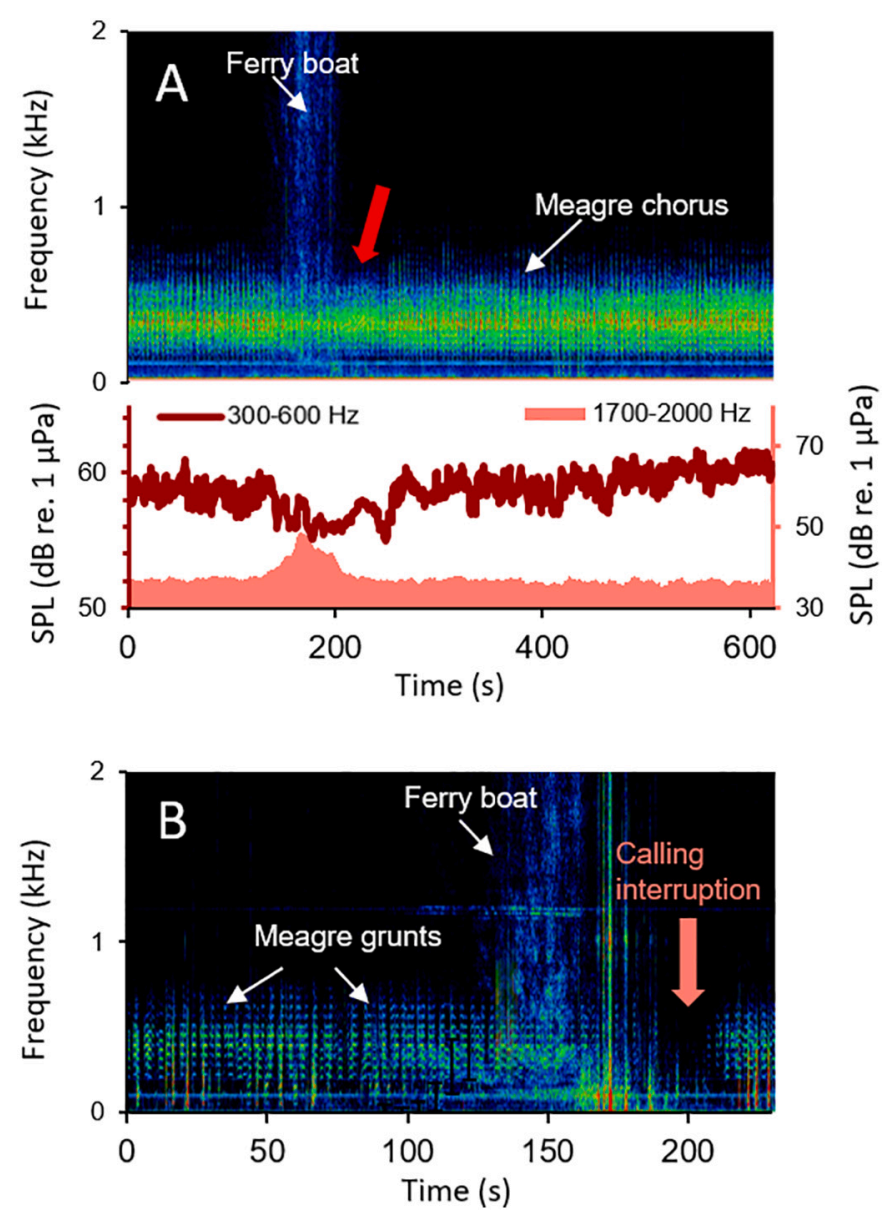

Fig. 9. Spectrograms with examples of the effect of boat passages on the meagre chorus. Boat passages usually caused a decrease in the chorus sound level during the passage of the boat (A) or even interrupted chorusing activity (B). In A it is also represented the SPL variation in two frequency bands (1700-2000 Hz and 300-600 Hz). The spectrogram in B shows a boat passage that also produced low frequency sounds originating from breaking waves. Note that a $50 \mathrm{~Hz}$ electrical noise (and respective harmonics) from the recording setup is also noticeable.

used to assess hearing sensitivity may reveal differences in the absolute hearing thresholds for a given species but provide similarly shaped threshold curves (Maruska and Sisneros, 2016). By comparing the meagre audiogram with the hearing sensitivity of other species evaluated with the same methods and in the same setup, the meagre exhibited a better hearing sensitivity than gobies (Amorim et al., 2018) and Lusitanian toadfish (Vasconcelos et al., 2007), except at low frequencies of ca. $50 \mathrm{~Hz}$, where the Lusitanian toadfish exhibited a better hearing threshold below $80 \mathrm{~dB}$ re. $1 \mu \mathrm{Pa}$. Notice, however, that the previous chronic exposure to noise in the rearing tanks might have affected the fishes' hearing sensitivity and increased auditory thresholds (Caiger et al., 2012).

\subsubsection{Conspecific calls and boat noise representation in the Auditory Evoked Potentials}

Meagre can accurately resolve temporal patterns of conspecific signals. AEP responses to the short grunts showed a clear representation of the stimuli pulse periods. The temporal pattern is thought to be the most important sound characteristic for acoustic communication in fishes (Hawkins and Rasmussen, 1978; Myrberg et al., 1978; Amorim et al., 2015). Wysocki and Ladich (2003) suggested that hearing of species without clear specialized structures might not be able to follow specific pulses of the stimulus, contrasting with species with hearing specialized 


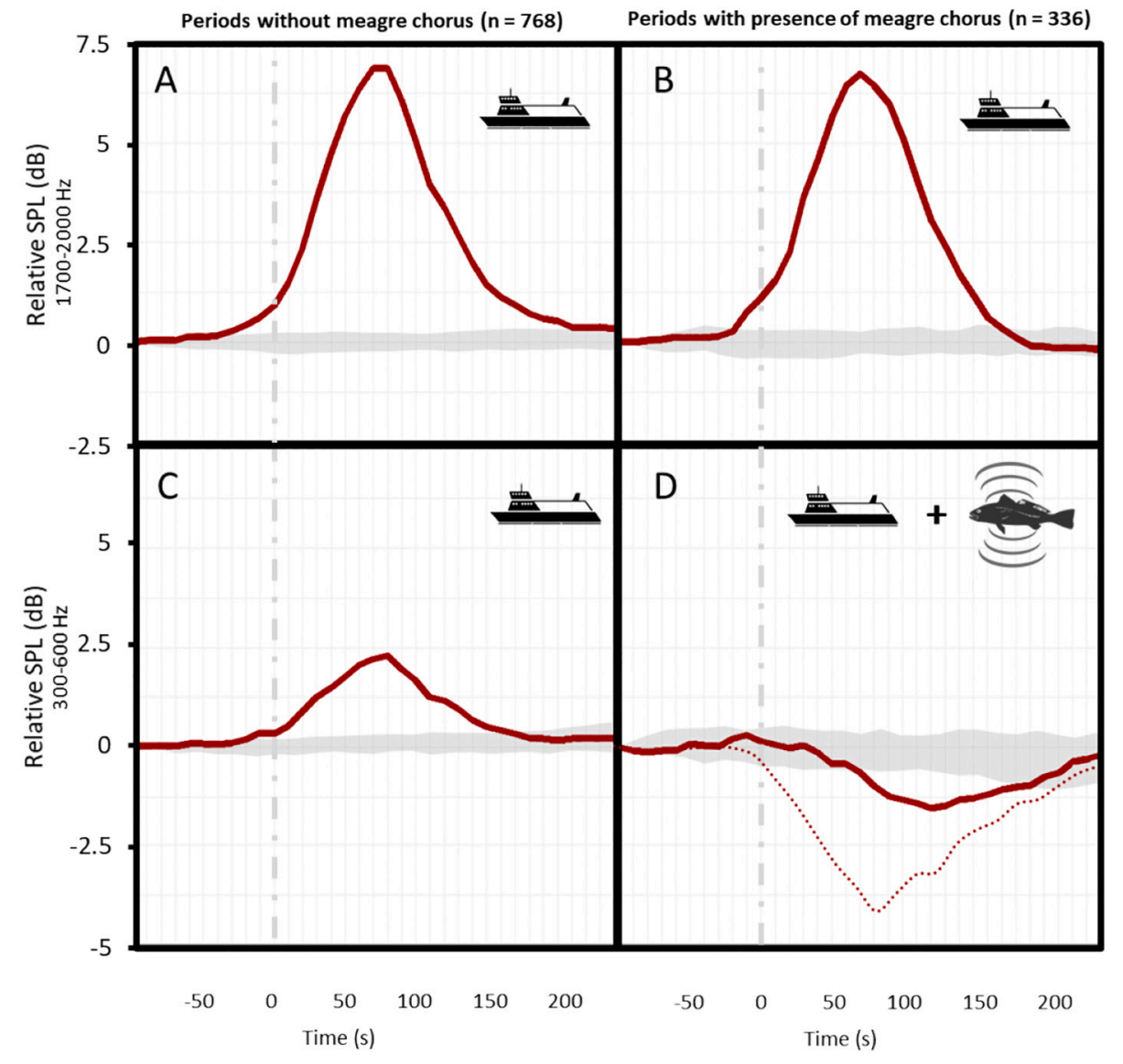

Fig. 10. Effect of boat passages on the meagre chorus sound level. Red line represents the mean SPL variation around ferryboats passages in two frequency bands $(1700-2000 \mathrm{~Hz}$ in A and B; $300-600 \mathrm{~Hz}$ in C and $D$ ). (A and $C$ ) represents sections without meagre chorus; and (B and D) represent ferryboat passages when in the presence of meagre chorus. Dotted line in (D) represents the results of the subtraction from $\mathrm{D}$ (solid line) of the values obtained in ( $\mathrm{C}$ - solid line), representing an approximate to the real effect on meagre chorus sound level. The Zero seconds mark represent the start-time of the ferryboat passages (according to the HMM recognition system). The light grey shadows refer to randomized sections (100 simulations) representing what should be expected if the boat passages did not affect the meagre chorus. SPL variation was calculated taking the value at $-100 \mathrm{~s}$ as reference. (For interpretation of the references to colour in this figure legend, the reader is referred to the web version of this article.)

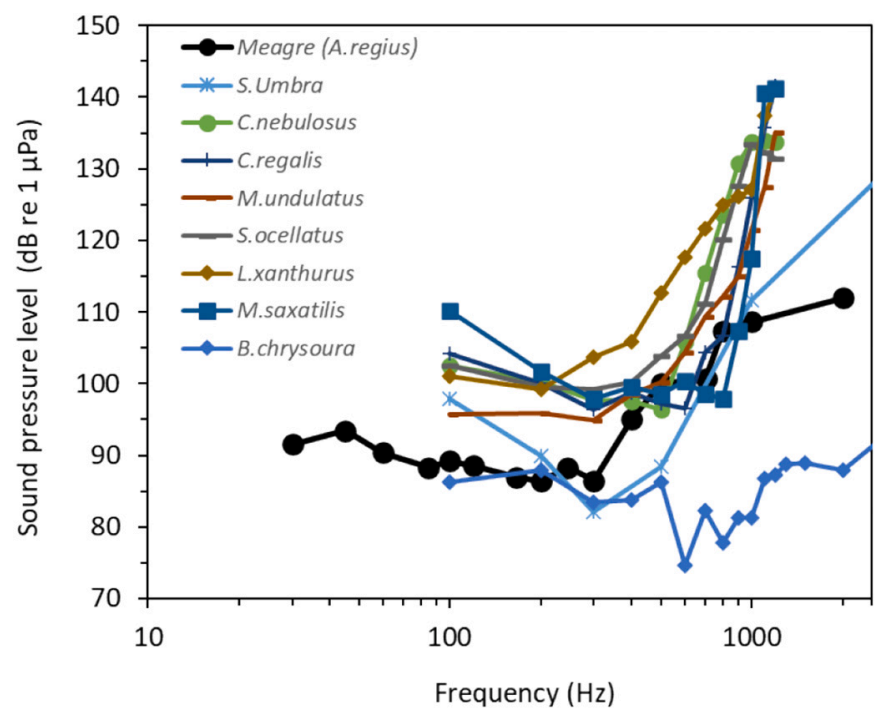

Fig. 11. Comparison of auditory pressure level thresholds between the juvenile meagre (current study) and other sciaenid species: Bairdiella chrysoura (Ramcharitar et al., 2004), Sciaena umbra (Wysocki et al., 2009), Cynoscion nebulosus, Cynoscion regalis, Micropogonias undulatus, Sciaenops ocellatus, Leiostomus xanthurus and Menticirrhus saxatilis (Horodysky et al., 2008). Audiograms result from the application of Auditory Evoked Potentials technique.

structures that can have a fine temporal resolution. The meagre hearing abilities clearly show enough resolution to properly encode temporal details of the several calls produced by this species, that mostly differ in the number of pulses (cf. Vieira et al., 2020). The Lusitanian toadfish, also presents fine temporal resolution comparable to those species possessing hearing specializations (Vasconcelos et al., 2011).

AEPs evoked by the conspecific calls showed spectral peaks corresponding to the harmonics presented in the sound spectrum but showing the characteristic frequency-doubling effect. This effect can be explained by the different orientations of the cilia of different saccular hair cells (Sand, 1976; Sisneros, 2007), and has been observed in other species (Mann et al., 2001; Higgs et al., 2003; Egner and Mann, 2005; Vasconcelos et al., 2011). Even though the spectral representation of the AEP responses is related to the stimuli, at lower signal-to-noise ratios the response to the stimulus is more noticeable on the temporal pattern than in the spectral domain.

Anthropogenic noise frequencies usually overlap with most known fish hearing frequency ranges, although human-generated sounds have usually a broader range that exceeds the upper limit of the hearing range of most fish species (Slabbekoorn et al., 2010). As expected, meagre hearing responded to boat noise as well, with the lower frequencies of the boat noise being represented in the AEPs (cf, Fig. 5B and the audiogram in Fig. 11). Furthermore, this supports the idea that fish can be directly distracted or stressed by boat noise (Dooling et al., 2015), and that masking of conspecific calls can occur in this species.

\subsubsection{Sensitivity to conspecific calls}

Our results indicate that the grunts can be detected down to a sound level close to the background level of the natural habitat, i.e. communication range should be limited by the background noise level, an assumption used in several studies (Fine and Lenhardt, 1983; Mann and Lobel, 1997; Lugli and Fine, 2003). On the other hand, Alves et al. (2016) using the AEPs of conspecific signals observed that the detection threshold was above the values expected by energetic masking, possible due to two factors: (1) the study used conspecific calls recorded at different distances adding the additional frequency degradation of the 
signal; (2) the detection threshold was defined with the representation of the acoustic signal envelope. Therefore, Alves et al. (2016) suggested that communication ranges estimated through energetic masking (Clark et al., 2009), i.e. sounds are detected if above the background noise, may overestimate fish communication range. Note that following Alves et al. (2016), we defined the detection thresholds by observing if the signal pulsed structure was correctly represented in the averaged AEPs.

A considerable variability was observed on the detection thresholds to conspecific calls in the absence of boat noise. Although the different grunts used (SG1, SG2 and SG3 in Fig. 2) might explain some variance, the differences observed might also be a result of variability of individual fish responses and/or small differences on the placement of the fish in the experimental tank and on the positioning of the electrodes. Such variability has been reported for different species. For example, in beluga whales (Delphinapterus leucas), Castellote et al. (2014) showed a high variability among individuals' detection thresholds (up to $11 \mathrm{~dB}$ s. d.). In fish, standard deviation of audiograms ranged between 2 and $7 \mathrm{~dB}$ in studies by Yan et al. (2000) and Vasconcelos et al. (2007). Variability of hearing sensitivity of multiple individuals to different stimuli is needed to properly use mathematical modelling to predict communication range.

\subsubsection{Boat noise masking effect assessed through the Auditory Evoked Potentials}

We evaluated how noise from two different boat types, ferryboat and small boat with an outboard engine, impacted the hearing of conspecific calls. As expected, our results show that boat noise produced a masking effect. The four noise samples of both boat types increased the detection threshold in ca. $20 \mathrm{~dB}$. Note that a reduction of ca. $20 \mathrm{~dB}$ on the ability of juvenile meagre to discriminate conspecific calls should be equivalent to ca. $90 \%$ reduction on the communication space (using the spherical spreading transmission loss as reported by Putland et al., 2017). To our knowledge only two other studies investigated the effect of boat noise on hearing of conspecific sounds in fishes, and in both cases significant masking was also observed (H. didactylus, Alves et al., 2021; C. chromis and $S$. umbra, Codarin et al., 2009). These are important pioneering studies since they addressed how boat noise masking effects can influence the ability of a fish's auditory pathway to detect and correctly represent conspecific calls, and so providing evidence on how anthropogenic noise can impact social acoustic communication.

The present results are consistent with other studies that estimated the increase of hearing thresholds to pure tones in the presence of boat noise (Vasconcelos et al., 2007; Codarin et al., 2009). Within the best hearing frequency range of the fish species studied by Vasconcelos et al. (2007, H. didactylus) and Codarin et al. (2009, C. chromis and S. umbra), the threshold-to-noise ratios of single tones increased ca. 10 to $38 \mathrm{~dB}$. Exposing fish to high noise amplitudes up to $158 \mathrm{~dB}$ re. $1 \mu \mathrm{Pa}$ caused temporary hearing loss or reduction in hearing sensitivity (Popper et al., 2003; Wysocki and Ladich, 2005; Breitzler et al., 2020). Such temporary threshold shifts might also occur in the meagre when exposed to high intensity sound (e.g., closer to the sound source). Furthermore, chronic noise in aquaculture facilities can also affect hearing thresholds (Caiger et al., 2012). Since fish used in this study came from an aquaculture facility and were kept in a tank equipped with cooler, external filter and aeration, it is conceivable that hearing thresholds and noise masking effects might be different in wild fish. Note, that we only assessed the ability to distinguish the temporal features of the conspecific call during exposure to boat noise at $130 \mathrm{~dB}$ re. $1 \mu \mathrm{Pa}$, corresponding approximately to the noise of a ferry boat passing in the relatively shallow area (ca. $5 \mathrm{~m}$ ) of the Tagus estuary where our study was conducted, and at a distance of ca. 50-100 m. Thus, higher impacts are expected at closer range from the source and similar masking effects are expected at larger distances in deeper waters of the estuary.

\subsubsection{Masking predictions}

The power spectrum model of masking was able to predict the masking of hearing of conspecific calls by the meagre caused by the boat noises close to the range of values estimated through AEPs. Using onethird octave bandwidth, in baseline conditions (no boat noise), the predicted detection grunt amplitudes ranged from 93 to $106 \mathrm{~dB}$ re. 1 $\mu \mathrm{Pa}$, while the estimated values from AEP response to short grunts were between stimuli amplitudes of 90 to $108 \mathrm{~dB}$ re. $1 \mu \mathrm{Pa}$. If $130 \mathrm{~dB}$ re. $1 \mu \mathrm{Pa}$ noise from small boats was present, the predicted grunt amplitudes allowing detection ranged between 115 and $128 \mathrm{~dB}$ re. $1 \mu \mathrm{Pa}$, close to the values inferred from the AEP recordings that ranged from 115 to 127 $\mathrm{dB}$ re. $1 \mu \mathrm{Pa}$. With playbacks of ferryboats' noise at $130 \mathrm{~dB}$ re. $1 \mu \mathrm{Pa}$, the predicted detection values for grunts ranged from 109 to $120 \mathrm{~dB}$ re. 1 $\mu \mathrm{Pa}$ while the AEP-based estimation was within 115 to $121 \mathrm{~dB}$ re. $1 \mu \mathrm{Pa}$. The detection of sounds in noisy conditions can occur based in parts of the calls. Using beluga whales, Erbe (2008) estimated masking based on behavioural detection threshold experiments and compared these thresholds with what would be expected from the power spectrum model of masking. They concluded that belugas could cue only on the peak low-frequency part of the call. This appears to be in accordance with our observations in the meagre.

Masking increases when the frequency spectra of the signal and the noise are very similar (Dooling et al., 2015). Thus, the frequency components and the sound levels of the noise and the signal are the critical variables for determining how detrimental a certain noise is for an animal's hearing. In the present study, boat noise elevated sound pressure levels by about $40 \mathrm{~dB}$ relative to background conditions similar to what can be observed in the Tagus estuary (Vasconcelos et al., 2007). However, the detection threshold increased only by ca. $20 \mathrm{~dB}$, which is explained by the change in sound level caused by the boat noise in the frequency band relevant for the meagre (Fig. 2).

Power spectrum models of masking including critical ratios and critical bandwidths are crucial to infer the effect of anthropogenic noise on the communication space of fishes (Putland et al., 2017). However, the literature of masking on aquatic animals is limited, with most research focused on marine mammals (Erbe et al., 2016). Table 1 shows how by using these principles, we can predict similar detection thresholds admitting that the critical bandwidths are close to one-third octave. Our results suggest that the critical bandwidth of the meagre may lie between $1 / 3$ and 1 octave. This is consistent with the only reported critical ratios on fish (Fay, 1998). Indeed, because the potential effects of noise in fishes is possibly similar to the ones described for mammals and birds, metrics as the critical ratio or critical bandwidth may be valuable for assessing masking effects of noise in fishes as well. Further work should infer these parameters in the meagre and other fish species.

\subsection{Fish vocal behaviour patterns}

The present study points to a decrease of the meagre calling activity when fish are exposed to boat passages. Sound level of meagre choruses usually decreased during boat passages, resuming sound levels shortly after. The observation of cases where call activity was interrupted, suggests that the sound level reductions was due to a decrease in the number of fish singing. A reduction in sound level might be also caused by fish moving away from boats which is reported to occur in fish in the presence of vessels (De Robertis and Handegard, 2013). However, if meagre were evading the vessels we would expect call energy to decrease (or increase) when fish moved away (or closer) from the hydrophone and resume upon their return, which was not the case. La Manna et al. (2016) observed the effect of boat passages on another sciaenid species, brown meagre $S$. umbra. In their study the fish increased the frequency of hiding behaviours but did not change call emission. Interestingly, Picciulin et al. (2012) observed that the brown meagre increased call rate with repeated boat passages, likely to compensate masking. Recently, Ceraulo et al. (2021) observed that black drum (Pogonias courbina), a south American sciaenid species, suppressed calling only when in presence of boat noise ranging the dominant frequencies of its calls. 
From the coping mechanisms fish can adopt, the meagre appears to perform noise avoidance through a decrease in the vocalization rate (Radford et al., 2014). This is in line with observations in Lusitanian toadfish during noise playback (Alves et al., 2021), and also with the reported lower calling activity of the Atlantic croaker (Micropogonias undulatus; Luczkovich et al., 2012) and the Oyster toadfish (Opsanus tau) in areas with heavier boat traffic (Luczkovich et al., 2016). Likewise, two goby species, produced fewer courtship sounds when exposed to prolonged continuous noise (de Jong et al., 2018), suggesting that noise may impair acoustic communication in various vocal fishes that rely on acoustic signals to attract and court mates. This decrease in acoustic signalling can also be a consequence of increased stress levels, which may then suppress reproductive behaviour, including acoustic signalling (Cox et al., 2018; de Jong et al., 2020). Furthermore, the results obtained using the AEP technique to assess hearing in the meagre suggest that exposure to anthropogenic noise can severely reduce the acoustic communication active space as reported for the Lusitanian toadfish (Alves et al., 2021). If perceived by fish, this masking effect could discourage call production as communication would not be effective during boat passages that produce noise on the same frequency band. Notice however, that the vocal activity changes observed could be due to a combination of visual, acoustic and mechanical stimuli caused by the boat passage.

Whether the short-term reactions of meagre to boat passages impact the reproductive behaviour likely linked to chorusing behaviour (Montie et al., 2017; Vieira et al., 2020) remains to be investigated. In other animal groups, a decrease in calling rate in presence of noise was also observed (e.g. insects: Gallego-Abenza et al., 2020; anurans: Caorsi et al., 2017, marine mammals: Van Parijs and Corkeron, 2001). Furthermore, several species go further in avoiding areas or periods with higher presence of anthropogenic noise (insects: Lampe et al., 2012; anurans: Herrera-Montes and Aide, 2011, Vargas-Salinas et al., 2014; birds: Halfwerk et al., 2011, Kight et al., 2012, Senzaki et al., 2020). This is recognized as a typical response to a stressor (Schreck, 2010), at least in some cases. A response to a stressor usually depends on a trade-off between the cost of being stressed and the cost of avoiding the stressor (Schreck et al., 2016). Animals may remain and reproduce or they might select areas less adequate, either way changes in behaviour or unavailability of the ideal conditions can also reduce reproductive success (e.g. in birds: Halfwerk et al., 2011; Kight et al., 2012; Senzaki et al., 2020). Studies addressing these possibilities are in need.

\section{Conclusions}

Human activities are transforming natural habitats and creating conditions to which animals must either adapt to or abandon (Katti and Warren, 2004). Here we characterized meagre hearing sensitivity and showed that anthropogenic noise can compromise conspecific mating signals detection. We observed a detrimental effect of boat noise passages in chorusing activity in wild meagre, further supporting the negative effect of boat noise in acoustic communication, which is key to breeding in this species. Our study stresses the importance of combining laboratory and field work to gain insight on boat noise impact and highlight the need to gain knowledge on coping mechanisms and fitness impacts in fish species. Although noise mitigation may be a complex problem to solve (Haren, 2007), we suggest that, as our results are concurrent with the negative effects of anthropogenic noise in other species and in different life stages (de Jong et al., 2020), actions to monitor and reduce anthropogenic noise should be undertaken.

\section{CRediT authorship contribution statement}

Manuel Vieira: Conceptualization, Formal analysis, Investigation, Methodology, Software, Visualization, Writing - original draft. Marilyn Beauchaud: Funding acquisition, Investigation, Methodology, Writing - review \& editing. M. Clara P. Amorim: Conceptualization, Funding acquisition, Project administration, Supervision, Writing - review \& editing. Paulo J. Fonseca: Conceptualization, Formal analysis, Funding acquisition, Methodology, Project administration, Supervision, Visualization, Writing - review \& editing.

\section{Declaration of competing interest}

The authors declare that they have no known competing financial interests or personal relationships that could have appeared to influence the work reported in this paper.

\section{Acknowledgements}

We thank the Air Force Base No. 6 of Montijo (Portugal) for allowing the field study in their military establishment, and IPMA-EPPO for the test subjects. This study was funded by the Science and Technology Foundation, Portugal, grant SFRH/BD/115562/2016 to M.V.; strategic projects UID/MAR/04292/2019 to M.C.P.A. by MARE and UID/BIA/ 00329/2019 to P.J.F. by cE3c; project PTDC/BIA-BMA/29662/2017 and by the University of Lyon/Saint Etienne, the Labex CeLyA and the CNRS.

\section{Appendix A. Supplementary data}

Supplementary data to this article can be found online at https://doi. org/10.1016/j.marpolbul.2021.112824.

\section{References}

Alloush, M., Scofield, D., Marczak, S., Jones, R., Kaiser, K., Oliva, M., Narins, P.M., Martineau, K., 2011. When sounds collide: the effect of anthropogenic noise on a breeding assemblage of frogs in Belize, Central America. Behaviour 148 (2), 215-232.

Alves, D., Amorim, M.C.P., Fonseca, P.J., 2016. Assessing acoustic communication active space in the Lusitanian toadfish. J. Exp. Biol. 219 (8), 1122-1129.

Alves, D., Vieira, M., Amorim, M.C.P., Fonseca, P.J., 2021. Boat noise interferes with Lusitanian toadfish acoustic communication. J. Exp. Biol. 224 (11), jeb234849.

Amorim, M.C.P., Vasconcelos, R.O., Fonseca, P.J., 2015. Fish sounds and mate choice. In: Sound Communication in Fishes. Springer, Vienna, pp. 1-33.

Amorim, M.C.P., Vasconcelos, R.O., Bolgan, M., Pedroso, S.S., Fonseca, P.J., 2018. Acoustic communication in marine shallow waters: testing the acoustic adaptive hypothesis in sand gobies. J. Exp. Biol. 221 (22).

Arroyo-Solís, A., Castillo, J.M., Figueroa, E., López-Sánchez, J.L., Slabbekoorn, H., 2013. Experimental evidence for an impact of anthropogenic noise on dawn chorus timing in urban birds. J. Avian Biol. 44 (3), 288-296.

Barber, J.R., Crooks, K.R., Fristrup, K.M., 2009. The costs of chronic noise exposure for terrestrial organisms. Trends Ecol. Evol. 25, 180-189.

Baum, L.E., Petrie, T., Soules, G., Weiss, N., 1970. A maximization technique occurring in the statistical analysis of probabilistic functions of markov chains. Ann. Math. Stat. 41 (1), 164-171.

Becker, A., Whitfield, A.K., Cowley, P.D., Järnegren, J., Næsje, T.F., 2013. Does boat traffic cause displacement of fish in estuaries? Mar. Pollut. Bull. 75 (1-2), 168-173.

Bee, M.A., Swanson, E.M., 2007. Auditory masking of anuran advertisement calls by road traffic noise. Anim. Behav. 74 (6), 1765-1776.

Blom, E.-L., Kvarnemo, C., Dekhla, I., Schöld, S., Andersson, M.H., Svensson, O., Amorim, M.C.P., 2019. Continuous but not intermittent noise has a negative impact on mating success in a marine fish with paternal care. Sci. Rep. 9, 5494.

Bowen, A.E., Gurule-Small, G.A., Tinghitella, R.M., 2020. Anthropogenic noise reduces male reproductive investment in an acoustically signaling insect. Behav. Ecol. Sociobiol. 74 (8), 1-8.

Breitzler, L., Lau, I.H., Fonseca, P.J., Vasconcelos, R.O., 2020. Noise-induced hearing loss in zebrafish: investigating structural and functional inner ear damage and recovery. Hear. Res. 107952.

Bruintjes, R., Radford, A.N., 2013. Context-dependent impacts of anthropogenic noise on individual and social behaviour in a cooperatively breeding fish. Anim. Behav. 85 (6), 1343-1349.

Brumm, H., Zollinger, S.A., 2013. Avian vocal production in noise. In: Animal Communication and Noise. Springer, Berlin, Heidelberg, pp. 187-227.

Caiger, P.E., Montgomery, J.C., Radford, C.A., 2012. Chronic low-intensity noise exposure affects the hearing thresholds of juvenile snapper. Mar. Ecol. Prog. Ser. 466, 225-232.

Caorsi, V.Z., Both, C., Cechin, S., Antunes, R., Borges-Martins, M., 2017. Effects of traffic noise on the calling behavior of two neotropical hylid frogs. PLoS One 12 (8), e0183342.

Castellote, M., Clark, C.W., Lammers, M.O., 2012. Acoustic and behavioural changes by fin whales (Balaenoptera physalus) in response to shipping and airgun noise. Biol. Conserv. 147 (1), 115-122. 
Castellote, M., Mooney, T.A., Quakenbush, L., Hobbs, R., Goertz, C., Gaglione, E., 2014. Baseline hearing abilities and variability in wild beluga whales (Delphinapterus leucas). J. Exp. Biol. 217 (10), 1682-1691.

Ceraulo, M., Sal Moyano, M.P., Hidalgo, F.J., Bazterrica, M.C., Mazzola, S., Gavio, M.A., Buscaino, G., 2021. Boat noise and black drum vocalizations in mar chiquita coastal lagoon (Argentina). J. Mar. Sci. Eng. 9 (1), 44.

Chao, L.N., 1986. In: Sciaenidae. Fishes of the North-eastern Atlantic and the Mediterranean, 2, pp. 865-874.

Clark, C.W., Ellison, W.T., Southall, B.L., Hatch, L., Van Parijs, S.M., Frankel, A., Ponirakis, D., 2009. Acoustic masking in marine ecosystems: intuitions, analysis, and implication. Mar. Ecol. Prog. Ser. 395, 201-222.

Codarin, A., Wysocki, L.E., Ladich, F., Picciulin, M., 2009. Effects of ambient and boat noise on hearing and communication in three fish species living in a marine protected area (Miramare, Italy). Mar. Pollut. Bull. 58 (12), 1880-1887.

Costello, R.A., Symes, L.B., 2014. Effects of anthropogenic noise on male signalling behaviour and female phonotaxis in oecanthus tree crickets. Anim. Behav. 95, $15-22$.

Cox, K., Brennan, L.P., Gerwing, T.G., Dudas, S.E., Juanes, F., 2018. Sound the alarm: a meta-analysis on the effect of aquatic noise on fish behavior and physiology. Glob. Chang. Biol. 24 (7), 3105-3116.

Cunnington, G.M., Fahrig, L., 2010. Plasticity in the vocalizations of anurans in response to traffic noise. Acta Oecol. 36 (5), 463-470.

De Robertis, A., Handegard, N.O., 2013. Fish avoidance of research vessels and the efficacy of noise-reduced vessels: a review. ICES J. Mar. Sci. 70 (1), 34-45.

Dooling, R.J., Leek, M.R., Popper, A.N., 2015. Effects of noise on fishes: what we can learn from humans and birds. Integrative Zoology 10 (1), 29-37.

Duarte, C.M., Chapuis, L., Collin, S.P., Costa, D.P., Devassy, R.P., Eguiluz, V.M., Erbe, C. Gordon, T.A.C., Halpern, B.S., Harding, H.R., Havlik, M.N., Meekan, M., Merchant, N.D., Miksis-Olds, J.L., Parsons, M., Predragovic, M., Radford, A.N., Radford, C.A., Simpson, S.D., Slabbekoorn, H., Staaterman, E., Van Opzeeland, I.C., Winderen, J., Zhang, X., Juanes, F., 2021. The soundscape of the Anthropocene ocean. Science (6529), 371.

Egner, S.A., Mann, D.A., 2005. Auditory sensitivity of sergeant major damselfish Abudefduf saxatilis from post-settlement juvenile to adult. Mar. Ecol. Prog. Ser. 285, 213-222.

Egnor, S.E.R., Hauser, M.D., 2006. Noise-induced vocal modulation in cotton-top tamarins (Saguinus oedipus). Am. J. Primatol. 68 (12), 1183-1190.

Erbe, C., 2008. Critical ratios of beluga whales (Delphinapterus leucas) and masked signal duration. J. Acoust. Soc. Am. 124 (4), 2216-2223.

Erbe, C., Farmer, D.M., 2000. A software model to estimate zones of impact on marine mammals around anthropogenic noise. J. Acoust. Soc. Am. 108 (3), 1327-1331.

Erbe, C., Reichmuth, C., Cunningham, K., Lucke, K., Dooling, R., 2016. Communication masking in marine mammals: a review and research strategy. Mar. Pollut. Bull. 103 (1-2), 15-38.

European Commission, 2008. Directive 2008/56/EC of the European Parliament and of the Council of 17 June 2008 establishing a framework for Community actions in the field of marine environmental policy (Marine Strategy Framework Directive. Off. J. Eur. Communities L164/19.

Fay, R.R., 1998. Comparative Hearing: Fish and Amphibians, Vol. 11. Springer Science \& Business Media.

Fine, M.L., Lenhardt, M.L., 1983. Shallow-water propagation of the toadfish mating call. Comp. Biochem. Physiol. A Physiol. 76 (2), 225-231.

Fletcher, H., 1940. Auditory patterns. Rev. Mod. Phys. 12, 47-65.

Forney, G.D., 1973. The viterbi algorithm. Proc. IEEE 61 (3), 268-278.

Fuller, R.A., Warren, P.H., Gaston, K.J., 2007. Daytime noise predicts nocturnal singing in urban robins. Biol. Lett. 3 (4), 368-370.

Gallego-Abenza, M., Mathevon, N., Wheatcroft, D., 2020. Experience modulates an insect's response to anthropogenic noise. Behav. Ecol. 31 (1), 90-96.

Gil, D., Brumm, H., 2014. Acoustic communication in the urban environment: patterns, mechanisms, and potential consequences of avian song adjustments. Avian Urban Ecol. 69-83.

Gil, M.D.M., Grau, A., Basilone, G., Ferreri, R., Palmer, M., 2013. Reproductive Strategy and Fecundity of Meagre Argyrosomus regius Asso, 1801 (Pisces: Sciaenidae): Implications for Restocking Programs.

Graham, A.L., Cooke, S.J., 2008. The effects of noise disturbance from various recreational boating activities common to inland waters on the cardiac physiology of a freshwater fish, the largemouth bass (Micropterus salmoides). Aquat. Conserv. Mar. Freshwat. Ecosyst. 18 (7), 1315-1324.

Haffray, P., Malha, R., Sidi, M.O.T., Prista, N., Hassan, M., Castelnaud, G., KarahanNomm, B., Gamsiz, K., Sadek, S., Bruant, J.S., Balma, P., Bonhomme, F., 2012. Very high genetic fragmentation in a large marine fish, the meagre Argyrosomus regius (Sciaenidae, Perciformes): impact of reproductive migration, oceanographic barriers and ecological factors. Aquat. Living Resour. 25 (2), 173-183.

Halfwerk, W., Holleman, L.J., Lessells, C.K.M., Slabbekoorn, H., 2011. Negative impact of traffic noise on avian reproductive success. J. Appl. Ecol. 48 (1), 210-219.

Hanache, P., Spataro, T., Firmat, C., Boyer, N., Fonseca, P., Médoc, V., 2020. Noiseinduced reduction in the attack rate of a planktivorous freshwater fish revealed by functional response analysis. Freshw. Biol. 65 (1), 75-85.

Haren, A.M., 2007. Reducing noise pollution from commercial shipping in the Channel Islands National Marine Sanctuary: a case study in marine protected area management of underwater noise. J. Int. Wildl. Law Policy 10 (2), 153-173.

Hawkins, A.D., Rasmussen, K.J., 1978. The calls of gadoid fish. J. Mar. Biol. Assoc. U. K. 58 (4), 891-911.

Herrera-Montes, M.I., Aide, T.M., 2011. Impacts of traffic noise on anuran and bird communities. Urban Ecosyst. 14 (3), 415-427.
Higgs, D.M., Souza, M.J., Wilkins, H.R., Presson, J.C., Popper, A.N., 2002. Age- and sizerelated changes in the inner ear and hearing ability of the adult zebrafish (Danio rerio). J. Assoc. Res. Otolaryngol. 3, 174-184.

Higgs, D.M., Rollo, A.K., Souza, M.J., Popper, A.N., 2003. Development of form and function in peripheral auditory structures of the zebrafish (Danio rerio). J. Acoust. Soc. Am. 113, 1145-1154.

Hinkley, D.V., 1988. Bootstrap methods. J. R. Stat. Soc. Ser. B Methodol. 50 (3), 321-337.

Holles, S., Simpson, S.D., Radford, A.N., Berten, L., Lecchini, D., 2013. Boat noise disrupts orientation behaviour in a coral reef fish. Mar. Ecol. Prog. Ser. 485, 295-300.

Horodysky, A.Z., Brill, R.W., Fine, M.L., Musick, J.A., Latour, R.J., 2008. Acoustic pressure and particle motion thresholds in six sciaenid fishes. J. Exp. Biol. 211 (9), 1504-1511.

Injaian, A.S., Poon, L.Y., Patricelli, G.L., 2018. Effects of experimental anthropogenic noise on avian settlement patterns and reproductive success. Behav. Ecol. 29 (5), 1181-1189.

Jensen, F.H., Bejder, L., Wahlberg, M., Soto, N.A., Johnson, M., Madsen, P.T., 2009. Vessel noise effects on delphinid communication. Mar. Ecol. Prog. Ser. 395, $161-175$.

Jerem, P., Mathews, F., 2021. Trends and knowledge gaps in field research investigating effects of anthropogenic noise. Conserv. Biol. 35 (1), 115-129.

de Jong, K., Amorim, M.C.P., Fonseca, P.J., Fox, C.J., Heubel, K.U., 2018. Noise can affect acoustic communication and subsequent spawning success in fish. Environ. Pollut. 237, 814-823.

de Jong, K., Forland, T.N., Amorim, M.C.P., Rieucau, G., Slabbekoorn, H., Sivle, L.D., 2020. Predicting the effects of anthropogenic noise on fish reproduction. Rev. Fish Biol. Fish. 1-24.

Katti, M., Warren, P.S., 2004. Tits, noise and urban bioacoustics. Trends Ecol. Evol. 19, 109-110.

Kenyon, T.N., 1996. Ontogenetic changes in the auditory sensitivity of damselfish (Pomacentridae). J. Comp. Physiol. A. 179, 553-561.

Kenyon, T.N., Ladich, F., Yan, H.Y., 1998. A comparative study of hearing ability in fishes: the auditory brainstem response approach. J. Comp. Physiol. A. 182 (3), 307-318.

Kight, C.R., Saha, M.S., Swaddle, J.P., 2012. Anthropogenic noise is associated with reductions in the productivity of breeding eastern bluebirds (Sialia sialis). Ecol. Appl. 22 (7), 1989-1996.

Klappert, K., Samarra, F., Miller, P., Brumm, H., 2009. Background noise constrains communication: acoustic masking of courtship song in the fruit fly Drosophila Montana. Behaviour 146 (12), 1635-1648.

Kunc, H.P., McLaughlin, K.E., Schmidt, R., 2016. Aquatic noise pollution: implications for individuals, populations, and ecosystems. Proc. R. Soc. B Biol. Sci. 283 (1836), 20160839.

La Manna, G., Manghi, M., Perretti, F., Sarà, G., 2016. Behavioral response of brown meagre (Sciaena umbra) to boat noise. Mar. Pollut. Bull. 110 (1), 324-334.

Ladich, F., 2013. Effects of noise on sound detection and acoustic communication in fishes. In: Animal Communication and Noise. Springer, Berlin, Heidelberg, pp. 65-90.

Lagardère, J.P., Mariani, A., 2006. Spawning sounds in meagre Argyrosomus regius recorded in the Gironde estuary, France. J. Fish Biol. 69 (6), 1697-1708.

Lampe, U., Schmoll, T., Franzke, A., Reinhold, K., 2012. Staying tuned: grasshoppers from noisy roadside habitats produce courtship signals with elevated frequency components. Funct. Ecol. 26 (6), 1348-1354.

Lengagne, T., 2008. Traffic noise affects communication behaviour in a breeding anuran, Hyla arborea. Biol. Conserv. 141 (8), 2023-2031.

Lohr, B., Wright, T.F., Dooling, R.J., 2003. Detection and discrimination of natural calls in masking noise by birds: estimating the active space of a signal. Anim. Behav. 65 (4), 763-777.

Luczkovich, J.J., Sprague, M.W., Johnson, S.E., Pullinger, R.C., 1999. Delimiting spawning areas of weakfish Cynoscion regalis (family Sciaenidae) in pamlico sound, North Carolina using passive hydroacoustic surveys. Bioacoustics 10 (2-3), 143-160.

Luczkovich, J.J., Krahforst, C.S., Sprague, M.W., 2012. Does vessel noise change the calling rate and intensity of soniferous fishes?. In: The Effects of Noise on Aquatic Life. Springer, New York, NY, pp. 375-378.

Luczkovich, J.J., Krahforst, C.S., Hoppe, H., Sprague, M.W., 2016. Does vessel noise affect oyster toadfish calling rates?. In: The Effects of Noise on Aquatic Life II. Springer, New York, NY, pp. 647-653.

Lugli, M., Fine, M.L., 2003. Acoustic communication in two freshwater gobies: ambient noise and short-range propagation in shallow streams. J. Acoust. Soc. Am. 114 (1), 512-521.

Mann, D.A., Lobel, P.S., 1997. Propagation of damselfish (Pomacentridae) courtship sounds. J. Acoust. Soc. Am. 101 (6), 3783-3791.

Mann, D.A., Higgs, D.M., Tavolga, W.N., Souza, M.J., Popper, A.N., 2001. Ultrasound detection by clupeiform fishes. J. Acoust. Soc. Am. 109, 3048-3054.

Maruska, K.P., Sisneros, J.A., 2016. Comparison of electrophysiological auditory measures in fishes. In: Fish Hearing and Bioacoustics. Springer, Cham, pp. 227-254.

McKenna, M.F., 2011. Blue Whale Response to Underwater Noise From Commercial Ships. UC San Diego.

Miller, P.J., Biassoni, N., Samuels, A., Tyack, P.L., 2000. Whale songs lengthen in response to sonar. Nature 405 (6789), 903.

Monfort, M.C., 2010. Present market situation and prospects of meagre (Argyrosomus regius), as an emerging species in Mediterranean aquaculture. In: Studies and Reviews-General Fisheries Commission for the Mediterranean, p. 89. 
Monroe, J.D., Manning, D.P., Uribe, P.M., Bhandiwad, A., Sisneros, J.A., Smith, M.E., Coffin, A.B., 2016. Hearing sensitivity differs between zebrafish lines used in auditory research. Hear. Res. 341, 220-231.

Montie, E.W., Hoover, M., Kehrer, C., Yost, J., Brenkert, K., O'Donnell, T., Denson, M.R., 2017. Acoustic monitoring indicates a positive relationship between calling frequency and spawning in captive spotted seatrout (Cynoscion nebulosus). PeerJ 4 e1656v1.

Myrberg, A.A., Spanier, E., Ha, S.J., 1978. Temporal patterning in acoustical communication. In: Contrasts in Behavior. Wiley, New York, pp. 137-179.

Nedelec, S.L., Radford, A.N., Pearl, L., Nedelec, B., McCormick, M.I., Meekan, M.G., Simpson, S.D., 2017. Motorboat noise impacts parental behaviour and offspring survival in a reef fish. Proc. R. Soc. B Biol. Sci. 284 (1856), 20170143.

Normandeau Associates, Inc, 2012. Effects of noise on fish, fisheries, and invertebrates in the U.S. Atlantic and Arctic from energy industry sound-generating activities. In: A Literature Synthesis for the U.S. Dept. of the Interior, Bureau of Ocean Energy Management.

Parsons, M., McCauley, R., Mackie, M., 2013. Characterisation of mulloway Argyrosomus japonicus advertisement sounds. Acoust. Aust. 41 (2), 141-146.

Pereira, B.P., Vieira, M., Pousão-Ferreira, P., Candeias-Mendes, A., Barata, M., Fonseca, P.J., Amorim, M.C.P., 2020. Sound production in the meagre, Argyrosomus regius (Asso, 1801): intraspecific variability associated with size, sex and context. PeerJ 8, e8559.

Picciulin, M., Sebastianutto, L., Codarin, A., Farina, A., Ferrero, E.A., 2010. In situ behavioural responses to boat noise exposure of Gobius cruentatus (Gmelin, 1789; fam. Gobiidae) and Chromis chromis (Linnaeus, 1758; fam. Pomacentridae) living in a Marine Protected Area. J. Exp. Mar. Biol. Ecol. 386 (1-2), 125-132.

Picciulin, M., Sebastianutto, L., Codarin, A., Calcagno, G., Ferrero, E.A., 2012. Brown meagre vocalization rate increases during repetitive boat noise exposures: a possible case of vocal compensation. J. Acoust. Soc. Am. 132 (5), 3118-3124.

Pine, M.K., Jeffs, A.G., Wang, D., Radford, C.A., 2016. The potential for vessel noise to mask biologically important sounds within ecologically significant embayments. Ocean Coast. Manag. 127, 63-73.

Popper, A.N., 1971. The effects of fish size on auditory capacities of the goldfish. J. Aud. Res. 11, 239-247.

Popper, A.N., Fay, R.R., 2011. Rethinking sound detection by fishes. Hear. Res. 273 $(1-2), 25-36$.

Popper, A.N., Hastings, M.C., 2009. The effects of anthropogenic sources of sound on fishes. J. Fish Biol. 75 (3), 455-489.

Popper, A.N., Hawkins, A.D., 2019. An overview of fish bioacoustics and the impacts of anthropogenic sounds on fishes. J. Fish Biol. 94 (5), 692-713.

Popper, A.N., Fewtrell, J., Smith, M.E., McCauley, R.D., 2003. Anthropogenic sound: effects on the behavior and physiology of fishes. Mar. Technol. Soc. J. 37 (4), 35-40.

Prista, N., Gordo, L., Costa, J.L., Costa, M.J., Jones, C., 2014. Reproductive phase determination in male meagre (Argyrosomus regius, Sciaenidae): testis development and histologic corroboration of a gross anatomical scale. Sci. Mar. 78 (1), 65-80.

Purser, J., Radford, A.N., 2011. Acoustic noise induces attention shifts and reduces foraging performance in three-spined sticklebacks (Gasterosteus aculeatus). PLoS One 6 (2), e17478.

Putland, R.L., Merchant, N.D., Farcas, A., Radford, C.A., 2017. Vessel noise cuts down communication space for vocalizing fish and marine mammals. Glob. Chang. Biol. 2 (4), 1708-1721. https://doi.org/10.1111/gcb.13996.

R Core Team, 2018. R: A Language and Environment for Statistical Computing. R Foundation for Statistical Computing, Vienna, Austria.

Radford, A.N., Kerridge, E., Simpson, S.D., 2014. Acoustic communication in a noisy world: can fish compete with anthropogenic noise? Behav. Ecol. 25 (5), 1022-1030.

Ramcharitar, J.U., Deng, X., Ketten, D., Popper, A.N., 2004. Form and function in the unique inner ear of a teleost: the silver perch (Bairdiella chrysoura). J. Comp. Neurol. 475 (4), 531-539.

Ramcharitar, J., Gannon, D.P., Popper, A.N., 2006. Bioacoustics of fishes of the family sciaenidae (croakers and drums). Trans. Am. Fish. Soc. 135 (5), 1409-1431.

Remage-Healey, L., Douglas, R., Nowacek, P., Bass, A.H., 2006. Dolphin foraging sounds suppress calling and elevate stress hormone levels in a prey species, the Gulf toadfish. J. Exp. Biol. 209, 4444-4451.

Richardson, W.J., Greene Jr., C.R., Malme, C.I., Thomson, D.H., 2013. Marine Mammals and Noise. Academic press.

Roca, I.T., Desrochers, L., Giacomazzo, M., Bertolo, A., Bolduc, P., Deschesnes, R., Martin, C.A., Rainville, V., Rheault, G., Proulx, R., 2016. Shifting song frequencies in response to anthropogenic noise: a meta-analysis on birds and anurans. Behav. Ecol. 27 (5), 1269-1274.

Rosa, P., Koper, N., 2018. Integrating multiple disciplines to understand effects of anthropogenic noise on animal communication. Ecosphere 9 (2), e02127.

Sand, O., 1976. Microphonic potentials as tool for auditory research in fish. In: Schuijf, A., Hawkins, A.D. (Eds.), Sound Reception in Fish. Elsevier Scientific Publishing Company, Amsterdam, The Netherlands, pp. 27-48.

Sarà, G., Dean, J.M., d'Amato, D., Buscaino, G., Oliveri, A., Genovese, S., Ferro, S., Buffa, G., Lo Martire, M., Mazzola, S., 2007. Effect of boat noise on the behaviour of bluefin tuna Thunnus thynnus in the Mediterranean Sea. Mar. Ecol. Prog. Ser. 331, 243-253.

Schreck, C.B., 2010. Stress and fish reproduction: the roles of allostasis and hormesis. Gen. Comp. Endocrinol. 165 (3), 549-556.

Schreck, C.B., Tort, L., Farrell, A.P., Brauner, C.J., 2016. Biology of Stress in Fish. Academic Press.

Sebastianutto, L., Picciulin, M., Costantini, M., Ferrero, E.A., 2011. How boat noise affects an ecologically crucial behaviour: the case of territoriality in Gobius cruentatus (Gobiidae). Environ. Biol. Fish 92 (2), 207-215.
Senzaki, M., Barber, J.R., Phillips, J.N., Carter, N.H., Cooper, C.B., Ditmer, M.A., Fristrup, K.M., McClure, C.J.W., Mennitt, D.J., Tyrrell, L.P., Vukomanovic, J., Wilson, A.A., Francis, C.D., 2020. Sensory pollutants alter bird phenology and fitness across a continent. Nature 1-5.

Shannon, G., McKenna, M.F., Angeloni, L.M., Crooks, K.R., Fristrup, K.M., Brown, E., Warner, K.A., Nelson, M.D., White, C., Briggs, J., McFarland, S., Wittemyer, G., 2015. A synthesis of two decades of research documenting the effects of noise on wildlife. Biol. Rev. 91 (4), 982-1005.

Sierra-Flores, R., Atack, T., Migaud, H., et al., 2015. Stress response to anthropogenic noise in Atlantic cod Gadus morhua L. Aquac. Eng. 67, 67-76.

Simmons, A.M., Narins, P.M., 2018. Effects of anthropogenic noise on amphibians and reptiles. In: Effects of Anthropogenic Noise on Animals. Springer, New York, NY, pp. 179-208.

Simpson, S.D., Purser, J., Radford, A.N., 2015. Anthropogenic noise compromises antipredator behaviour in european eels. Glob. Chang. Biol. 21 (2), 586-593.

Sisneros, J.A., 2007. Saccular potentials of the vocal plainfin midshipman fish, Porichthys notatus. J. Comp. Physiol. A. 193, 413-424.

Sisneros, J.A., Bass, A.H., 2005. Ontogenetic changes in the response properties of individual, primary auditory afferents in the vocal plainfin midshipman fish Porichthys notatus Girard. J. Exp. Biol. 208, 3121-3131.

Slabbekoorn, H., 2019. Noise pollution. Curr. Biol. 29 (19), R957-R960.

Slabbekoorn, H., Bouton, N., van Opzeeland, I., Coers, A., ten Cate, C., Popper, A.N., 2010. A noisy spring: the impact of globally rising underwater sound levels on fish. Trends Ecol. Evol. 25 (7), 419-427.

Stanley, J.A., Van Parijs, S.M., Hatch, L.T., 2017. Underwater sound from vessel traffic reduces the effective communication range in Atlantic cod and haddock. Sci. Rep. 7 (1), 1-12.

Sun, J.W., Narins, P.M., 2005. Anthropogenic sounds differentially affect amphibian call rate. Biol. Conserv. 121 (3), 419-427.

Taylor, M.D., Fowler, A.M., Suthers, I.M., 2020. Insights into fish auditory structure-function relationships from morphological and behavioural ontogeny in a maturing sciaenid. Mar. Biol. 167 (2), 1-11.

Tressler, J., Smotherman, M.S., 2009. Context-dependent effects of noise on echolocation pulse characteristics in free-tailed bats. J. Comp. Physiol. A. 195 (10), 923-934.

Tuset, V.M., Otero-Ferrer, J.L., Gómez-Zurita, J., Venerus, L.A., Stransky, C., Imondi, R., Orlov, A.M., Ye, Z., Santschi, L., Afanasiev, P.K., Zhuang, L., Farré, M., Love, M.S., Lombarte, A., 2016. Otolith shape lends support to the sensory drive hypothesis in rockfishes. J. Evol. Biol. 29 (10), 2083-2097.

Van Parijs, S.M., Corkeron, P.J., 2001. Boat traffic affects the acoustic behaviour of Pacific humpback dolphins, Sousa chinensis. Marine Biological Association of the United Kingdom. J. Mar. Biol. Assoc. U. K. 81 (3), 533.

Vargas-Salinas, F., Cunnington, G.M., Amézquita, A., Fahrig, L., 2014. Does traffic noise alter calling time in frogs and toads? A case study of anurans in eastern Ontario. Canada. Urban Ecosystems 17 (4), 945-953.

Vasconcelos, R.O., Ladich, F., 2008. Development of vocalization, auditory sensitivity and acoustic communication in the lusitanian toadfish Halobatrachus didactylus. J. Exp. Biol. 211 (4), 502-509.

Vasconcelos, R.O., Amorim, M.C.P., Ladich, F., 2007. Effects of ship noise on the detectability of communication signals in the lusitanian toadfish. J. Exp. Biol. 210 (12), 2104-2112.

Vasconcelos, R.O., Fonseca, P.J., Amorim, M.C.P., Ladich, F., 2011. Representation of complex vocalizations in the lusitanian toadfish auditory system: evidence of fine temporal, frequency and amplitude discrimination. Proc. R. Soc. B Biol. Sci. 278 (1707), 826-834.

Vasconcelos, R.O., Carriço, R., Ramos, A., Modesto, T., Fonseca, P.J., Amorim, M.C.P. 2012. Vocal behavior predicts reproductive success in a teleost fish. Behav. Ecol. 23, 375-383.

Vieira, M., Fonseca, P.J., Amorim, M.C.P., Teixeira, C.J., 2015. Call recognition and individual identification of fish vocalizations based on automatic speech recognition: an example with the Lusitanian toadfish. J. Acoust. Soc. Am. 138 (6), 3941-3950.

Vieira, M., Amorim, M.C.P., Fonseca, P.J., 2021. Vocal rhythms in nesting Lusitanian toadfish, Halobatrachus didactylus. Ecol. Inform. 63, 101281.

Vieira, M., Pereira, B.P., Pousão-Ferreira, P., Fonseca, P.J., Amorim, M., 2019. Seasonal variation of captive meagre acoustic signalling: a manual and automatic recognition approach. Fishes 4 (2), 28.

Vieira, M., Amorim, M.C.P., Sundelöf, A., Prista, N., Fonseca, P.J, 2020. Underwater noise recognition of marine vessels passages: two case studies using hidden Markov models. ICES J. Mar. Sci. 77 (6), 2157-2170.

Voellmy, I.K., Purser, J., Flynn, D., Kennedy, P., Simpson, S.D., Radford, A.N., 2014. Acoustic noise reduces foraging success in two sympatric fish species via different mechanisms. Anim. Behav. 89, 191-198.

Wang, J., Song, Q., Yu, D., Yang, G., Xia, L., Su, K., Shi, H., Wang, J., Yin, S., 2015. Ontogenetic development of the auditory sensory organ in zebrafish (Danio rerio) changes in hearing sensitivity and related morphology. Sci. Rep. 5 (1), 1-15.

Wysocki, L.E., Ladich, F., 2001. The ontogenetic development of auditory sensitivity, vocalization and acoustic communication in the labyrinth fish Trichopsis vittata. J. Comp. Physiol. A. 187, 177-187.

Wysocki, L.E., Ladich, F., 2003. The representation of conspecific sounds in the auditory brainstem of teleost fishes. J. Exp. Biol. 206 (13), 2229-2240.

Wysocki, L.E., Ladich, F., 2005. Effects of noise exposure on click detection and the temporal resolution ability of the goldfish auditory system. Hear. Res. 201 (1-2), 27-36. 
Wysocki, L.E., Codarin, A., Ladich, F., Picciulin, M., 2009. Sound pressure and particle acceleration audiograms in three marine fish species from the Adriatic Sea. J. Acoust. Soc. Am. 126 (4), 2100-2107.
Yan, H.Y., Fine, M.L., Horn, N.S., Colon, W.E., 2000. Variability in the role of the gasbladder in fish audition. J. Comp. Physiol. A. 186 (5), 435-445.

Young, S., Evermann, G., Gales, M., 2006. The HTK Book Version 3.4. Cambridge University Press, Cambridge, UK. 